\title{
Los sistemas de protección social, la redistribución y el crecimiento en América Latina
}

\author{
José Antonio Ocampo y Natalie Gómez-Arteaga
}

\section{Resumen}

Tras revisar el debate entre los méritos relativos del universalismo y de la focalización de la política social, este trabajo evalúa el estado actual y los retos de los sistemas de protección social en América Latina. Muestra la amplia, aunque todavía desigual, expansión de estos sistemas en la región entre 2003 y 2013. En particular, persisten desigualdades considerables en el acceso a la protección social por tipo de empleo y nivel de ingresos familiares. Las coberturas de los sistemas contributivos son bajas y, si bien las de los regímenes no contributivos se han expandido, en general sus prestaciones son reducidas. En este sentido, la incidencia del gasto social mediante transferencias directas es aún baja en comparación con los países desarrollados. El documento también muestra que la expansión de los sistemas de protección social ha contribuido más a la reducción de la pobreza que el crecimiento del producto interno bruto (PIB).

Palabras clave

Política social, seguridad social, igualdad, distribución del ingreso, gastos públicos, mitigación de la pobreza, crecimiento económico, medición, América Latina

Clasificación JEL

13, H22, H23

Autores

José Antonio Ocampo es Profesor de la Universidad de Columbia; fue Secretario General Adjunto de las Naciones Unidas para Asuntos Económicos y Sociales, Secretario Ejecutivo de la Comisión Económica para América Latina y el Caribe (CEPAL) y Ministro de Hacienda y Crédito Público, Ministro de Agricultura y Desarrollo Rural y Director del Departamento Nacional de Planeación de Colombia. ocampo.joseantonio@yahoo.com

Natalie Gómez-Arteaga es Funcionaria del Departamento Nacional de Planeación de Colombia; fue Investigadora Asociada en la Iniciativa para el Diálogo Político de la Universidad de Columbia, y Consultora de la Organización Internacional del Trabajo (OIT) y del Programa de las Naciones Unidas para el Desarrollo (PNUD). natalie.gomezarteaga@gmail.com 


\section{Introducción ${ }^{1}$}

Entre 2003 y 2013, los indicadores sociales de América Latina mejoraron de manera significativa, y en la mayoría de los países de la región se redujo la desigualdad de ingresos, en fuerte contraste con la tendencia mundial hacia el aumento de la desigualdad que se ha observado tanto en los países desarrollados como en los países en desarrollo. Esta mejora coincidió con un desempeño económico adecuado, particularmente entre 2003 y 2008, ya que entre 2008 y 2013 se produjo una desaceleración. La combinación de la mejora de la distribución del ingreso y el crecimiento económico razonable se tradujo en una reducción masiva de la pobreza, la más rápida desde la década de 1970. Además de las condiciones externas favorables (los elevados precios de los productos básicos y un amplio acceso a financiamiento externo), los factores que impulsaron las mejoras de esta "década de oro social" fueron el desarrollo de programas innovadores de protección social y un mejor estado de bienestar. En la región han ido surgiendo nuevas formas de protección social, que incluyen pensiones universales o de base amplia en Bolivia (Estado Plurinacional de), el Brasil y Chile, sistemas de salud universales en el Brasil y Colombia, el creciente interés por los programas de transferencias monetarias condicionadas y transferencias universales como las asignaciones por hijo en la Argentina. En el Ecuador y el Uruguay, entre otros países de la región, se han expandido los pilares contributivos de la seguridad social, y en la Argentina y el Estado Plurinacional de Bolivia se ha revertido la privatización de las pensiones. Estos avances también se han visto acompañados de progresos en otras dimensiones, como el aumento significativo de los salarios y la rápida expansión del acceso a la educación, aunque con diferencias significativas de calidad.

Con la reciente mejora e innovación de sus sistemas de protección social, y a pesar de la diversidad que caracteriza a la región, puede afirmarse que América Latina está alejándose poco a poco del antiguo enfoque centrado en subsidios estatales focalizados y volviendo a los conceptos básicos sobre los que se construyó el estado de bienestar en los países industriales, en torno al universalismo y la solidaridad que definen a una política social basada en el principio de ciudadanía social. De hecho, la expansión de los sistemas de protección social en América Latina se opone a la experiencia reciente del resto del mundo, en especial la de las economías avanzadas, donde desde mediados de la década de 1990 las reformas han mermado la generosidad de las prestaciones sociales y reducido la progresividad de los regímenes del impuesto sobre la renta, trazando una política fiscal menos redistributiva (Bastagli, Coady y Gupta, 2012). En varios países de ingresos altos y medios estas tendencias han llevado a reformar los sistemas de protección social: se han reducido los programas universales más costosos y se han ampliado los programas focalizados, cuyos beneficios son más limitados y demandan menos recursos. En este contexto, resulta esencial evaluar los efectos positivos que la reciente expansión de los sistemas de protección social ha tenido en la reducción de la pobreza y la desigualdad en América Latina y su relación con el desarrollo económico a la hora de efectuar recomendaciones de política, no solo referidas a América Latina sino también a otros países de ingresos medios o bajos que están construyendo sus propios estados de bienestar.

Este trabajo analiza el debate entre la focalización y el universalismo de la política social y evalúa las mejoras recientes de 18 países de América Latina en tres dimensiones de la protección social: la universalidad, la solidaridad y el gasto público. Entre 2002 y 2012, 15 de los 18 países mejoraron su puntuación en el índice de protección social desarrollado para este estudio, lo que significa que experimentaron diferentes combinaciones de una mayor cobertura de salud y pensiones, menores brechas de cobertura entre los asalariados y los no asalariados, más gasto social y una mejor cobertura de la asistencia social en el quintil más pobre. Sin embargo, persisten grandes desigualdades, tanto por tipo de empleo como por nivel de ingresos. En general, es menos probable que los trabajadores

\footnotetext{
1 Los autores agradecen los aportes y comentarios de Isabel Ortiz y Christina Behrendt, de la Organización Internacional del Trabajo, durante la elaboración de este ensayo, así como el valioso apoyo de María José Abud como asistente de investigación.
} 
no asalariados estén afiliados a sistemas de salud y pensiones, y la cobertura de pensiones sigue siendo muy deficiente en términos de bajas tasas de afiliación de la población ocupada y de acceso a una pensión durante la vejez.

El gasto social ha incidido de forma significativa en la pobreza y la desigualdad. El efecto redistributivo es mayor en el caso de las transferencias indirectas que en el de las directas, lo que demuestra que, a pesar de ser altamente progresivas, las transferencias directas focalizadas tienen una cobertura y unos beneficios reducidos. En cualquier caso, la redistribución fiscal es menor en América Latina que en los países desarrollados, debido a una combinación menos progresiva de impuestos con transferencias y beneficios sociales limitados.

En este período de desaceleración económica, en el que algunos países ya están experimentando recesiones y las proyecciones de crecimiento económico en el futuro inmediato siguen siendo débiles - particularmente en América del Sur-, continuar y reforzar la expansión del estado de bienestar con prestaciones universales podría revelarse una estrategia esencial, dado que, según muestran los datos, la redistribución no está reñida con el crecimiento. De hecho, los países de América Latina que cuentan con mayor protección y gasto social han tenido tasas de crecimiento más altas. Sin embargo, para ofrecer una mejor protección es necesario diseñar sistemas tributarios con impuestos más altos y progresivos.

Tras esta Introducción, el trabajo se divide en otras seis secciones. La sección II estudia el debate entre el universalismo y la focalización de las políticas sociales en América Latina desde una amplia perspectiva histórica. La sección III identifica las mejoras de los sistemas de protección social durante el último decenio, midiendo su amplitud y universalidad mediante un índice multidimensional. La sección IV analiza el estado actual de los sistemas de protección social y pone de relieve la persistente segmentación del acceso a la salud y las pensiones. La sección $\vee$ evalúa la incidencia del gasto social en la pobreza y la desigualdad. La sección VI muestra la interrelación entre la expansión de los sistemas de protección social, el crecimiento económico y la reducción de la pobreza, y la sección VII concluye con algunas recomendaciones generales.

\section{El debate entre el universalismo y la focalización de la política social}

La forma moderna de concebir la política social tiene sus raíces en la visión liberal de que la provisión de educación básica y servicios de salud es inherente al progreso de las sociedades modernas. A partir de finales del siglo XIX, la creación de los sistemas modernos de seguridad social bajo el liderazgo de Bismarck y las demandas provenientes de los movimientos sindicales y socialistas dieron origen a visiones más integrales de la política social. El resultado de este proceso, así como de la competencia con el comunismo durante la posguerra, fue el desarrollo del estado de bienestar en las principales economías industriales desde la década de 1930. Un corolario importante de este desarrollo fue el crecimiento sin precedentes del tamaño del Estado.

En América Latina también se manifestaron estas visiones, pero sus impactos fueron más limitados. Las reformas introducidas en el Uruguay por el Presidente Batlle y Ordóñez en la década de 1910 representan tal vez las manifestaciones más tempranas de esta tendencia. El enfoque más exhaustivo del estado de bienestar solo se materializó en unos pocos países: los del Cono Sur (Argentina, Chile y Uruguay) y Costa Rica². No obstante, el estado de bienestar nunca llegó a desarrollarse en estos países como en los países industrializados, particularmente en términos del

\footnotetext{
2 A esta lista podría sumarse Cuba a partir de la revolución de 1958; no obstante, al tener un sistema económico, social y político totalmente diferente, el país queda fuera de este análisis.
} 
diseño de sistemas integrales de impuestos y transferencias para reducir la desigualdad de ingresos. En la mayoría de los países de América Latina, hasta mediados del siglo XX la cobertura fue baja incluso en el caso de los servicios básicos de salud y educación, y el desarrollo de la seguridad social fue tardío y su alcance limitado por estar asociada al empleo formal y tener un trasfondo corporativista. El resultado fue un estado de bienestar incompleto y segmentado que beneficiaba solo a algunos sectores medios de la sociedad y tendía a marginar a los pobres, particularmente los de las áreas rurales (Bértola y Ocampo, 2013, capítulos I y IV).

Las reformas que tuvieron lugar en el mercado en las décadas de 1980 y 1990 relegaron la política social a una posición subordinada ${ }^{3}$. La nueva visión de la política social que empezó a difundirse por toda América Latina en la década de 1980 queda ilustrada en tres instrumentos de reforma de la política social en los que el Banco Mundial centró su agenda para la región: la focalización, los subsidios a la demanda orientados a facilitar un sistema que contara con la participación del sector privado y la descentralización. El primero intentaba que la política social fuera coherente con los limitados recursos fiscales, a la vez que ayudaba a los pobres, en tanto que los otros dos abordaban la necesidad de racionalizar el aparato estatal. A estos instrumentos se sumaron toda una serie de proyectos específicos diseñados para gestionar los costos sociales de la reforma estructural, entre los que destacan especialmente los fondos sociales de emergencia.

La aplicación de estos nuevos principios en la región fue desigual. La focalización de la política social tuvo su mejor manifestación en los programas de transferencias monetarias condicionadas, que se desarrollaron inicialmente como mecanismos de emergencia (el programa Solidaridad, en México) o como un instrumento para garantizar una cobertura más amplia de los servicios de educación básica (el programa Bolsa Escola, en el Brasil). Con el tiempo, evolucionaron hacia una cobertura más amplia, con el propósito de alcanzar eventualmente la cobertura universal en su población objetivo, y acabaron siendo rebautizados como Prospera y Bolsa Família. Estos mecanismos fueron copiados por otros países, y supusieron la punta de lanza de lo que Ferreira y Robalino (2011) han denominado la "revolución de la asistencia social".

Como resultado de estas reformas, los sistemas actuales de la política social en América Latina combinan tres modelos diferentes, incluso a veces dentro de un mismo país. El primero es el sistema universal en sentido estricto, que funciona esencialmente como un servicio prestado por el sector público con diferentes grados de descentralización, como el que caracteriza a los sistemas educativos, donde existen diversos niveles de participación del sector privado, en particular en la educación universitaria. El segundo es el sistema segmentado y corporativista heredado del pasado, que sigue prevaleciendo en la provisión de la seguridad social (salud, pensiones y riesgos ocupacionales) de varios países. El tercero son los esquemas focalizados estrictos, cuya manifestación más representativa son los programas de transferencias condicionadas. Filgueira y otros (2006, pág. 37) consideran los sistemas de política social resultantes como un corporativismo persistente mezclado con elementos liberales. Estos sistemas no cuentan con un pilar de derechos claramente definidos y, lo que es más, al carecer de la coherencia y el atractivo del viejo concepto del estado de bienestar, no pueden servir como instrumentos centrales para la cohesión social.

El retorno del universalismo como paradigma de la política social está estrechamente ligado a los conceptos de derechos sociales y ciudadanía social. En el plano internacional, esta visión se reflejó en el auge del estado de bienestar y el desarrollo de los derechos económicos, sociales y culturales resumidos en los artículos 22 a 27 de la Declaración Universal de Derechos Humanos, y más adelante en el Pacto Internacional de Derechos Económicos, Sociales y Culturales de las Naciones Unidas, así como en instrumentos similares adoptados por la Organización de los Estados Americanos. Este

\footnotetext{
3 Esto se refleja, por ejemplo, en la ausencia de menciones a la política social en los diez principios del consenso de Washington resumidos por Williamson (1990), excepto como una prioridad del gasto público.
} 
nuevo conjunto de derechos expresa nociones modernas de igualdad, solidaridad y no discriminación que se remontan al concepto de ciudadanía social de Thomas H. Marshall (véase su ensayo original de 1950 reproducido en Marshall, 1992). Además, como se indica en el preámbulo de la Carta de las Naciones Unidas, estos derechos deben ser concebidos como la manifestación de la voluntad de los Estados Miembros de "promover el progreso social" y "elevar el nivel de vida dentro de un concepto más amplio de la libertad", un concepto que se remonta a la libertad para vivir sin miseria que postulaba Franklin D. Roosevelt y que más recientemente ha sido retomado por Amartya Sen con su concepto de desarrollo como libertad (Sen, 2000). En América Latina, esta visión también ha sido expresada por el Programa de las Naciones Unidas para el Desarrollo en su concepción de la democracia como una extensión de las tres dimensiones de la ciudadanía (civil, política y social) (PNUD, 2004; véase también Ocampo, 2007) y por la Comisión Económica para América Latina y el Caribe (CEPAL) en recientes documentos institucionales sobre la igualdad, particularmente en su llamado a promover pactos para la igualdad (CEPAL, 2014a).

La formulación más precisa de este concepto en América Latina es el capítulo sobre los principios de la política social del informe Equidad, desarrollo y ciudadanía de la CEPAL (2000). Los cuatro principios formulados son: universalidad, solidaridad, eficiencia e integralidad. El primero de ellos encierra la visión de que los beneficios de la política social son más que servicios o mercancías: son derechos y, por lo tanto, deben ser garantizados a todos los ciudadanos por igual. El segundo alude a algo que es especialmente evidente en las sociedades que presentan altos niveles de desigualdad: la garantía de acceso de la población pobre a estos derechos debería basarse en el principio de solidaridad, que además expresa el objetivo básico de crear sociedades más incluyentes. El tercero señala que debería asegurarse la utilización óptima de los recursos disponibles para los programas de bienestar social, y el último recuerda que existen muchas dimensiones de la pobreza y la desigualdad y que estas deben abordarse simultáneamente.

En materia de protección social, en 2008 la Conferencia Internacional del Trabajo (CIT) adoptó la histórica Declaración de la Organización Internacional del Trabajo sobre la Justicia Social para una Globalización Equitativa. La Declaración institucionaliza el concepto de "trabajo decente", que la Organización Internacional del Trabajo (OIT) viene desarrollando desde 1999 para promover una globalización justa. Este concepto engloba un enfoque integral que identifica el empleo, el diálogo social, los derechos laborales y la protección social (incluida "la ampliación de la seguridad social a todas las personas") como objetivos estratégicos (OIT, 2008). Como seguimiento de esta Declaración, en la $101^{\text {a }}$ reunión de la Conferencia Internacional del Trabajo, celebrada en 2012, 184 miembros aprobaron por unanimidad la recomendación número 202, en la que se proporciona orientación para el establecimiento y mantenimiento de los pisos de protección social como un elemento central de los sistemas nacionales de seguridad social, para garantizar el acceso universal a la atención básica de salud y una renta básica para todos durante el ciclo de vida (OIT, 2012).

Como se verá en la siguiente sección, durante el último decenio los países de América Latina han logrado grandes avances hacia el desarrollo de sistemas de protección social más universales y exhaustivos basados en los conceptos de ciudadanía social y trabajo decente. 


\section{Un índice multidimensional para medir los sistemas de protección social en América Latina}

El índice de protección social empleado en este artículo mide el progreso de 18 países de América Latina en tres dimensiones de los sistemas de protección social - universalidad, solidaridad y gasto social ${ }^{4}$ - sobre la base de nueve indicadores, como se puede observar en el diagrama 1.

Diagrama 1

América Latina: índice de protección social
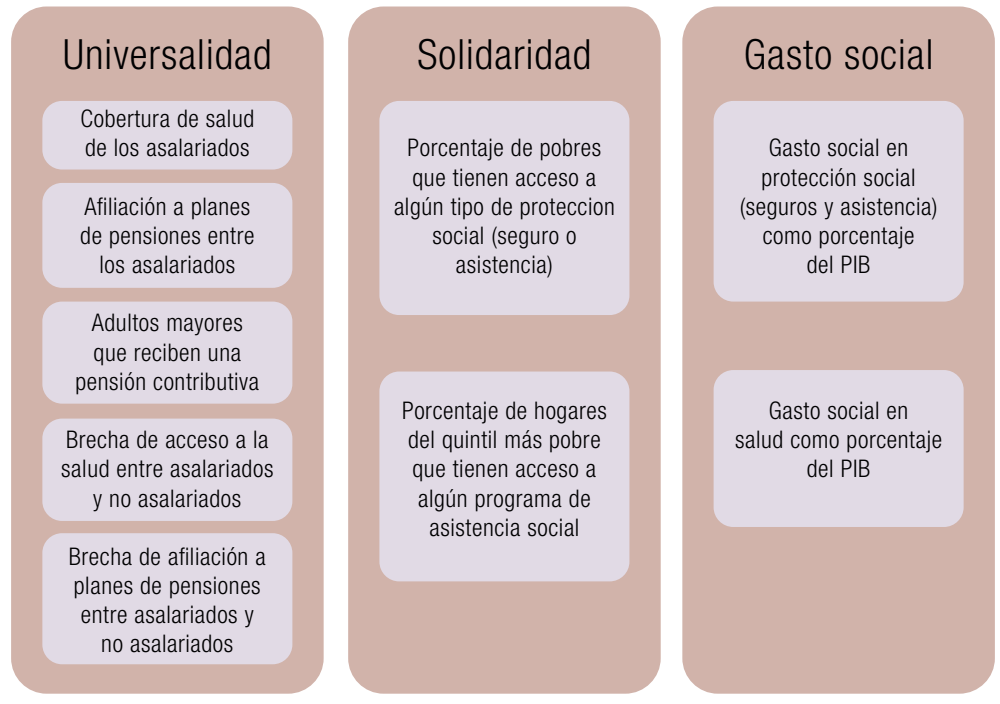

Fuente: Elaboración propia.

Nota: PIB: Producto interno bruto.

La primera dimensión, la universalidad, mide la cobertura de la atención de salud y de los planes de pensiones (en ambos regímenes: seguros o asistencia social) de la población activa y el porcentaje de población que recibe una pensión durante la vejez. Debido a la segmentación histórica de los sistemas de protección social en América Latina, producto de su vínculo con el empleo formal ${ }^{5}$, esta dimensión incluye dos indicadores que miden la brecha de la cobertura de salud y pensiones entre los trabajadores asalariados y los no asalariados ${ }^{6}$. Los datos provienen del Panorama Social de América Latina 2013 (CEPAL, 2013), en el que se prestó especial atención al acceso a la atención de salud y a las pensiones en la región.

\footnotetext{
4 Las dimensiones del índice buscan reflejar los principios de un estado de bienestar bien desarrollado. Ante la imposibilidad de obtener una aproximación de la eficiencia y la integralidad, se utiliza el gasto público en los sistemas de protección social como variable indicativa para estos criterios (véase a continuación).

5 Véanse Barrientos (2011) y Kaplan y Levy (2014).

6 Entre los trabajadores no asalariados se incluye a empleadores, trabajadores por cuenta propia, socios de cooperativas de productores y trabajadores familiares no remunerados. Debido a la falta de información, los indicadores de cobertura miden solo los datos relacionados con los trabajadores asalariados. Por medio de este indicador y los que miden la brecha de cobertura entre los dos tipos de empleo se obtiene una aproximación del grado de universalidad de los sistemas de protección social.
} 
Evidentemente, la cobertura universal debería extenderse también a otras áreas de los sistemas de protección social, e incluso a la seguridad social ${ }^{7}$ en su sentido más amplio, pero los únicos datos que se hallaban disponibles en los países en dos momentos específicos (alrededor de 2002 y alrededor de 2012) eran los referidos a la afiliación a planes de salud y pensiones de la población en edad de trabajar (la fuerza de trabajo activa), en los que se diferenciaba entre los asalariados y los no asalariados, y al porcentaje de personas mayores que recibían una pensión contributiva. Los datos disponibles no permiten medir la protección relacionada con las personas con discapacidad o los riesgos ocupacionales, y otros programas como las prestaciones por desempleo son deficientes en la región: solo algunos países las ofrecen y generalmente tienen muy baja cobertura, dado que por lo general se suelen basar en la afiliación a la seguridad social ${ }^{8}$.

La segunda dimensión, la solidaridad, puede estimarse por medio de dos indicadores: uno que mide el acceso de los hogares más pobres a alguna forma de protección social y otro que determina la eficacia de la focalización de la asistencia social ${ }^{9}$ entre los pobres. El primero de ellos corresponde al porcentaje de hogares pobres (en términos multidimensionales) que cuentan con algún tipo de protección social, es decir, donde al menos uno de sus integrantes tiene acceso a un seguro de salud, contribuye al sistema de pensiones o recibe una pensión de vejez o jubilación. Este indicador es uno de los componentes del índice de pobreza multidimensional para América Latina propuesto por la Oxford Poverty and Human Development Initiative (OPHI) y está incluido en el Panorama Social de América Latina 2013 (CEPAL, 2013). La eficacia de la focalización de la asistencia social se mide con base en la cobertura de todos los programas de asistencia social en el quintil más pobre de la población a partir de datos del Banco Mundial.

Finalmente, la última dimensión mide el gasto social del sector público en salud y protección social (seguro y asistencia social) como porcentaje del PIB. La comparación entre países sugiere que cuanto mayor es el presupuesto para gasto social, mejores son los resultados en términos de reducción de la pobreza y la desigualdad. Por otra parte, el tamaño del presupuesto también refleja el contrato social y el tipo de instituciones existentes en un determinado país, así como la universalidad del sistema. La hipótesis es que el tamaño del presupuesto destinado a la redistribución no es fijo, y las estructuras institucionales del estado de bienestar son propensas a afectar la forma como los ciudadanos definen su identidad e intereses. Por lo tanto, un modelo institucional de estado de bienestar basado en una estrategia universalista con un presupuesto elevado destinado a mantener los estándares de vida normales o habituales seguramente generará una mayor redistribución que un modelo más modesto basado en la focalización (Korpi y Palme, 1998, pág. 663). Si bien este índice puede tener ciertas limitaciones y omitir algunas variables, como veremos en las próximas secciones, es una referencia útil para el propósito de este trabajo y un indicador aproximado para medir los cambios de los sistemas de protección social.

Se crearon índices estandarizados para cada uno de los nueve indicadores del índice de protección social utilizando referentes mínimos y máximos (metas) de los países analizados. Para los indicadores de cobertura se usó como meta la cobertura del 100\%, mientras que para los indicadores

\footnotetext{
7 Según la OIT, la noción de los pisos de protección social incluye el acceso a la atención básica de salud, incluido el cuidado maternoinfantil; la seguridad de ingresos básicos de los niños, suficientes para brindar acceso a su nutrición, educación, cuidado y otros bienes y servicios esenciales para su bienestar; la seguridad de ingresos básicos para personas en edad activa que sean incapaces de obtener suficientes ingresos, en particular en casos de enfermedad, desempleo, maternidad y discapacidad, y la seguridad de ingresos básicos para las personas mayores. En su sentido más amplio, la seguridad social abarca ocho áreas: prestaciones monetarias de enfermedad, prestaciones por desempleo, prestaciones de vejez, prestaciones en caso de accidentes de trabajo, prestaciones familiares, prestaciones de maternidad, prestaciones de invalidez o discapacidad y prestaciones de sobrevivientes.

8 Según los datos de la OIT sobre protección social, Chile y el Uruguay cuentan con la mayor cobertura de los regímenes de desempleo de América Latina y el Caribe: alcanzan a un 27\% y un 29\% de la población, respectivamente.

9 La asistencia social consiste en todas aquellas prestaciones que están focalizados en los grupos vulnerables de la población, especialmente los hogares pobres. La mayoría de los programas de asistencia social están sujetos a verificación de la necesidad.
} 
de la brecha de cobertura se usó la del 0\%. El índice final es una medición aproximada basada en el promedio aritmético de los índices estandarizados de cada uno de los nueve indicadores (un promedio simple en el que todos los indicadores tienen el mismo peso) ${ }^{10}$. El índice final tiene un rango del 0 al 1, donde 1 representa el sistema más integral, que ofrece una cobertura relativamente universal, menos desigualdad en lo que respecta a la afiliación a los sistemas de salud y pensión de vejez en los distintos tipos de empleo, un alto grado de inclusión social, una asistencia social bien orientada y un elevado gasto social (véase la descripción y fuente de cada indicador en el anexo A1).

En el gráfico 1 puede observarse la puntuación final de los países en el índice de protección social en 2002 y 2012. A partir del resultado del índice de protección social de 2012, se dividieron los países en tres categorías en términos del alcance y la universalidad de los sistemas de protección social: i) el Uruguay, Chile, Costa Rica, la Argentina y el Brasil, con las puntuaciones más altas, se caracterizaron por tener los sistemas más integrales; ii) Venezuela (República Bolivariana de), Colombia, el Perú, México, el Ecuador, la República Dominicana y Panamá tenían sistemas intermedios, y iii) El Salvador, el Paraguay, Bolivia (Estado Plurinacional de), Nicaragua, Guatemala y Honduras se caracterizaron por tener sistemas de protección social relativamente limitados. Esta clasificación concuerda con otras realizadas en el mismo ámbito, que concluyen que los países del Cono Sur, que presentan un grado de desarrollo más elevado, han construido estados de bienestar más completos. Por su parte, Costa Rica siempre se ha destacado por tener un estado de bienestar bastante universal, a pesar de un producto interno bruto (PIB) per cápita mucho menor que los países del Cono Sur (Cecchini y Martínez, 2012).

\section{Gráfico 1}

América Latina (18 países): puntuación en el índice de protección social, alrededor de 2002 y $2012^{a}$

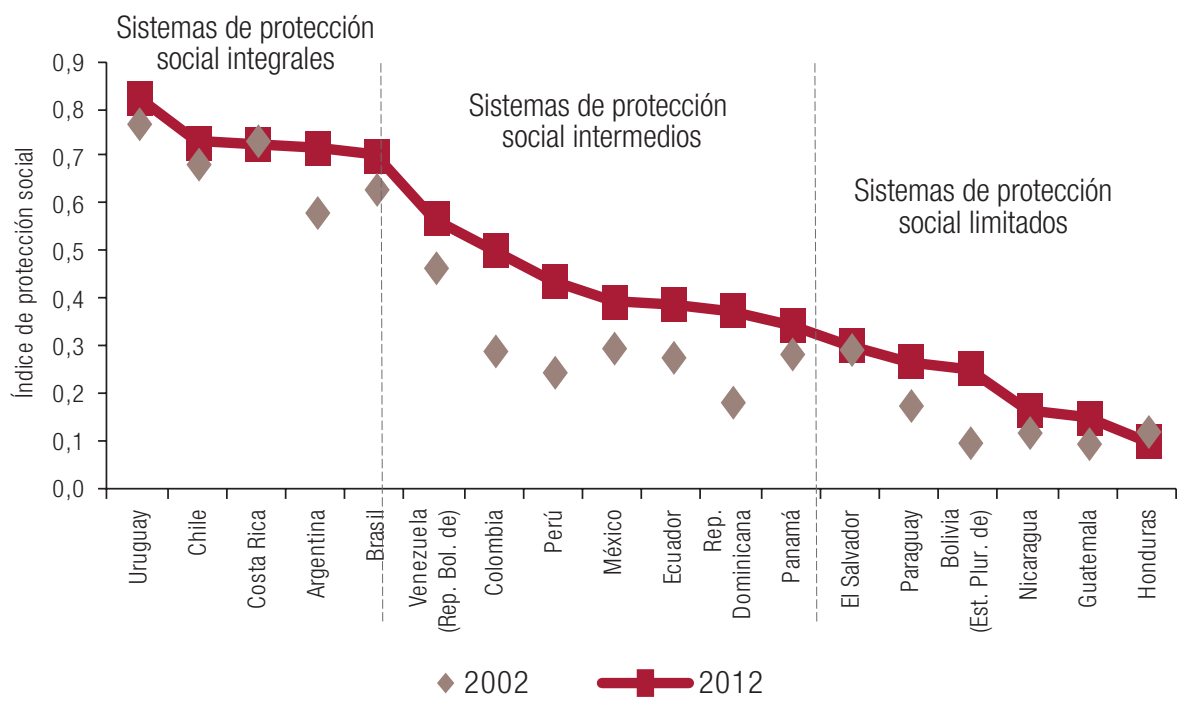

Fuente: Elaboración propia, sobre la base de datos de la Comisión Económica para América Latina y el Caribe (CEPAL), Panorama Social de América Latina 2013 (LC/G.2580), Santiago, 2013; Panorama Social de América Latina 2014 (LC/G.2635-P), Santiago, 2013; M.E. Santos y otros, "A multidimensional poverty index for Latin America", OPHI Working Paper, № 79, Universidad de Oxford, 2015; y Banco Mundial.

Nota: El índice de protección social es el promedio aritmético de los resultados estandarizados de cada país en los nueve indicadores utilizados para clasificarlos.

a "Alrededor de 2012" incluye años comprendidos entre 2010 y 2013.

10 El promedio aritmético solo tiene en cuenta indicadores en los que no falte información. De los 18 países, 9 cuentan con información completa de los 9 indicadores (Argentina, Bolivia (Estado Plurinacional de), Chile, Colombia, Ecuador, El Salvador, Paraguay, Perú y Uruguay), 1 país (República Bolivariana de Venezuela) tiene información completa de 5 indicadores y el resto, de 7 indicadores. 
Entre 2002 y 2012, 15 de los 18 países con información disponible mejoraron su puntuación en el índice de protección social. Esto significa que experimentaron mejoras relevantes en al menos una de las dimensiones de la protección social, lo que denota un avance hacia un sistema más universal e integral. En contraste, los tres restantes no mostraron cambios representativos en el índice.

Los países con un sistema de protección social intermedio fueron los que más mejoraron. Colombia exhibió la mejora más notable en la puntuación del índice de protección social, seguida por el Perú, la República Dominicana y un país con un sistema de protección social limitado, el Estado Plurinacional de Bolivia. En el caso de Colombia, el avance fue el resultado de los esfuerzos realizados para alcanzar la cobertura de salud universal por medio de un régimen subsidiado dirigido a los pobres y a los trabajadores independientes ${ }^{11}$. La cobertura de salud en Colombia incrementó significativamente tanto para los trabajadores asalariados como para los no asalariados, y se redujo la brecha de afiliación entre ambos tipos de trabajadores. Mientras que en 2002 el 53\% de los trabajadores asalariados tenían acceso a protección de salud, en 2012 se había alcanzado el 91\%. El aumento de la cobertura entre los trabajadores no asalariados, además, redujo la brecha entre los dos tipos de empleo: de 75 puntos porcentuales en 2002 a 5 puntos en 2012. Perú, el país que registró la segunda mejora más significativa en la puntuación del índice, logró también progresos relevantes en el acceso a la atención de salud y las pensiones, cuyos indicadores casi se duplicaron entre 2002 y 2012, y en el mismo período la cobertura de los programas de asistencia social del quintil más pobre pasó de menos de un $10 \%$ al $70 \%$.

En el Estado Plurinacional de Bolivia el acceso al sistema de pensiones contributivas de las personas mayores mejoró significativamente: la cobertura aumentó del 13\% al 21\%. Si bien este nivel es aún bajo comparado con otros países, se logró una cobertura casi universal entre las personas de edad (mayores de 65 años) a través de un régimen no contributivo (véase la sección IV). Entre los países con sistemas integrales, la Argentina fue el que más mejoró, principalmente gracias a la expansión del sistema de pensiones, que introdujo una jubilación básica obligatoria para todos, independientemente de si el beneficiario había cumplido o no el período mínimo de cotizaciones requerido ${ }^{12}$.

En el cuadro 1 se muestran los valores medios de los nueve indicadores incluidos en el índice de protección social, por categorías de sistemas de protección social, en 2012. Como era de esperar, los países con sistemas de protección social más integrales obtienen mejores resultados, en promedio, en ocho de los nueve indicadores. Por ejemplo, mientras que el $82 \%$ de la población mayor de los países con un sistema de protección social integral tiene acceso a una pensión y, por lo tanto, a la seguridad de un ingreso en la vejez, en los países con sistemas de protección social intermedios o limitados solo el $28 \%$ y el $15 \%$ de las personas mayores, respectivamente, cuentan con ese beneficio. La brecha de cobertura entre los países con sistemas integrales y aquellos con sistemas limitados es extensa en lo que respecta a las pensiones de vejez y el porcentaje de hogares pobres que disfrutan de algún tipo de protección. En los países con sistemas integrales, el porcentaje de personas mayores de 65 años que reciben una pensión es cinco veces mayor al de los países con un sistema limitado. Asimismo, el porcentaje de hogares pobres que acceden a algún tipo de protección social es tres veces mayor en los países con sistemas integrales que en aquellos con sistemas limitados.

\footnotetext{
11 Véase el estudio de caso del Banco Mundial sobre la cobertura universal de salud en Colombia (Montenegro y Acevedo, 2013).

12 Véase Lustig y Pessino (2013). La moratoria previsional, introducida en 2004/05, permitió que los trabajadores en edad de jubilación recibieran una pensión, independientemente de si habían completado el período requerido de 30 años de cotizaciones a la seguridad social a través de un empleo formal.
} 
Cuadro 1

América Latina (países seleccionados)a: valor medio de los indicadores del índice de protección social por categoría del sistema, 2012

(En porcentajes)

\begin{tabular}{|c|c|c|c|c|c|c|c|c|c|}
\hline $\begin{array}{l}\text { Categoría del } \\
\text { sistema de } \\
\text { protección } \\
\text { social }\end{array}$ & $\begin{array}{c}\text { Cobertura de } \\
\text { las pensiones } \\
\text { contributivas } \\
\text { (mayores } \\
\text { de } 65 \text { años) }\end{array}$ & $\begin{array}{l}\text { Asalariados } \\
\text { afiliados } \\
\text { a sistemas } \\
\text { de pensiones }\end{array}$ & $\begin{array}{l}\text { Asalariados } \\
\text { afiliados } \\
\text { a sistemas } \\
\text { de salud }\end{array}$ & $\begin{array}{c}\text { Brecha de } \\
\text { acceso } \\
\text { a planes de } \\
\text { pensiones } \\
\text { entre } \\
\text { trabajadores } \\
\text { asalariados y } \\
\text { no asalariados }\end{array}$ & $\begin{array}{c}\text { Brecha de } \\
\text { acceso a la } \\
\text { salud entre } \\
\text { trabajadores } \\
\text { asalariados } \\
\text { y no } \\
\text { asalariados }\end{array}$ & $\begin{array}{l}\text { Hogares } \\
\text { pobres con } \\
\text { acceso a } \\
\text { algún tipo de } \\
\text { protección } \\
\text { social }\end{array}$ & $\begin{array}{l}\text { Cobertura } \\
\text { del quintil } \\
\text { más pobre } \\
\text { (todo tipo de } \\
\text { asistencia } \\
\text { social) }\end{array}$ & $\begin{array}{c}\text { Gasto } \\
\text { social en } \\
\text { protección } \\
\text { social como } \\
\text { porcentaje } \\
\text { del PIB }\end{array}$ & $\begin{array}{c}\text { Gasto } \\
\text { social } \\
\text { en salud } \\
\text { como } \\
\text { porcentaje } \\
\text { del PIB }\end{array}$ \\
\hline Integral & 81,8 & 77,1 & 90,0 & -52 & -12 & 92,8 & 65,0 & 9,9 & 5,1 \\
\hline Intermedio & 28,4 & 58,3 & 75,1 & -70 & -42 & 71,3 & 68,6 & 3,7 & 2,1 \\
\hline Limitado & 15,3 & 37,6 & 41,9 & -96 & -79 & 44,9 & 63,3 & 3,3 & 2,7 \\
\hline
\end{tabular}

Fuente: Elaboración propia, sobre la base de datos de la Comisión Económica para América Latina y el Caribe (CEPAL), Panorama Social de América Latina 2013 (LC/G.2580), Santiago, 2013; Panorama Social de América Latina 2014 (LC/G.2635-P), Santiago, 2013; M.E. Santos y otros, "A multidimensional poverty index for Latin America", OPHI Working Paper, № 79, Universidad de Oxford, 2015; y Banco Mundial.

Nota: PIB: Producto interno bruto.

a Argentina, Bolivia (Estado Plurinacional de), Brasil, Chile, Colombia, Costa Rica, Ecuador, El Salvador, Guatemala, Honduras, México, Nicaragua, Panamá, Paraguay, Perú, República Dominicana, Uruguay y Venezuela (República Bolivariana de).

El único indicador en el que no hay diferencias claras entre las categorías de sistemas de protección social es el que mide la cobertura de la asistencia social en el quintil más pobre; de hecho, los países con un sistema intermedio parecen lograr una focalización más eficiente, pues presentan una mayor cobertura entre la población del primer quintil. Dada la magnitud de algunos programas de asistencia social en la región, principalmente los programas de transferencias monetarias condicionadas, no resulta extraño que los niveles de cobertura sean similares en todos los países. En efecto, dados sus exiguos niveles de gasto y su deficiente cobertura de salud y pensiones, los países de ingresos bajos tienden a priorizar los programas sujetos a verificación, por lo que es posible que muestren una cobertura mayor que los países con un sistema de protección social integral (Ferreira y Robalino, 2011). En los últimos años, países como Colombia, México y el Perú han continuado mejorando sus mecanismos de focalización para llegar a los hogares más pobres y expandir sus programas de transferencias monetarias condicionadas (véase el caso de Colombia en Angulo y Gómez, 2015).

Las recientes mejoras en el índice de protección social están ligadas a los esfuerzos de los países por desarrollar sistemas de protección social más universales y con políticas específicas para incluir a la población pobre y la informal, tradicionalmente excluidas. Sin embargo, como se verá a continuación, existe todavía una gran segmentación en el acceso y las prestaciones de los sistemas de protección social según el tipo de empleo y el nivel de ingresos.

\section{Segmentación persistente, pero menor, en los sistemas de protección social de la región}

Innovaciones recientes como, entre otras, los mecanismos contributivos flexibles, las pensiones básicas de la Argentina, las pensiones no contributivas del Estado Plurinacional de Bolivia y de Chile y 
la cobertura de salud universal de Colombia, con un gran componente de solidaridad, han contribuido a mejorar el acceso a la atención de salud y las pensiones en toda la región $n^{13}$.

Entre 2002 y 2012, el acceso a pensiones y salud aumentó en toda la región, tanto para los trabajadores asalariados como para los no asalariados y en todos los niveles de ingresos. Gracias a los esfuerzos de la región por alcanzar la atención de salud universal y por resolver la falta de cobertura de la población informal, la cobertura de salud ha mejorado especialmente entre los trabajadores no asalariados y los quintiles más bajos de la distribución del ingreso (véase el gráfico 2).

Gráfico 2

América Latina (países seleccionados)a : afiliación a sistemas de salud y pensiones por tipo de empleo y por quintil de ingreso, alrededor de 2002 y 2012

(En porcentajes)

Trabajadores asalariados

Trabajadores no asalariados

80

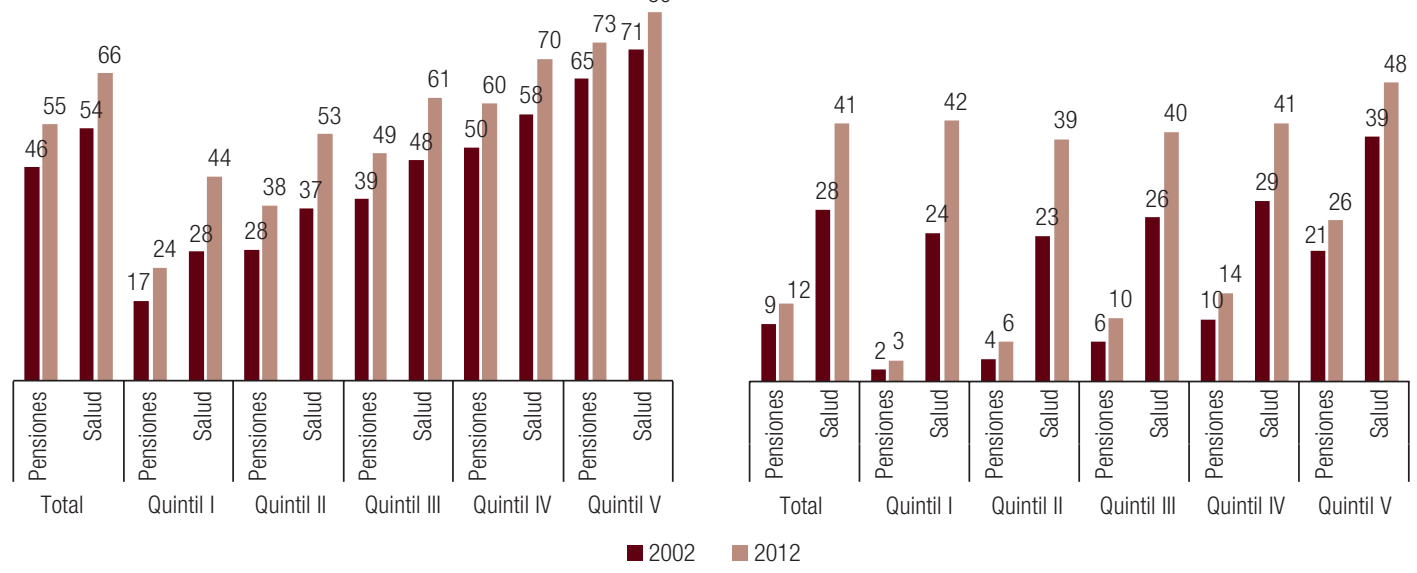

Fuente: Comisión Económica para América Latina y el Caribe (CEPAL), Panorama Social de América Latina 2013 (LC/G.2580), Santiago, 2013.

a Argentina, Bolivia (Estado Plurinacional de), Brasil, Chile, Colombia, Costa Rica, Ecuador, El Salvador, Guatemala, Honduras, México, Nicaragua, Panamá, Paraguay, Perú, República Dominicana, Uruguay y Venezuela (República Bolivariana de).

El porcentaje de trabajadores no asalariados con acceso a atención de salud casi se ha duplicado durante el último decenio, mientras que el acceso a los sistemas de pensiones solo se ha incrementado tres puntos porcentuales. Independientemente del tipo de empleo o del quintil de ingresos, existe una propensión mayor a tener un seguro de salud que a estar afiliado a un plan de pensiones, lo que refleja el mayor impacto redistributivo de la atención de salud que de las transferencias, como se verá en la sección V.

Las recientes innovaciones que buscan eliminar la segmentación o truncamiento del acceso a la protección social por tipo de empleo son una clara manifestación del cambio de paradigma que se ha producido en la región en los últimos años en pro del universalismo. A finales del siglo XX, cuando se hizo evidente que el problema del alcance limitado de la protección social (que solo cubría a

${ }^{13}$ El índice de acceso a la atención de salud y las pensiones cuantifica a la población en edad de trabajar (personas de 15 años o más) afiliada a algún tipo de seguro de salud (independientemente del tipo de esquema de financiación) y algún plan de pensiones (público o privado). El acceso a pensiones también se mide por el porcentaje de personas mayores que reciben esta prestación. 
personas con una ocupación formal afiliadas a un régimen contributivo) no se iba a resolver por sí mismo a medida que los países se desarrollaban ${ }^{14}$, fueron surgiendo en toda la región mecanismos innovadores para proveer alguna forma de protección básica para todos, especialmente para los trabajadores por cuenta propia. Además del ejemplo ya mencionado del régimen subsidiado en Colombia, en 2001 el Uruguay puso en marcha un régimen de monotributo para mejorar la cobertura de los trabajadores por cuenta propia: mediante un proceso simplificado, se unificaron diferentes impuestos y contribuciones a la seguridad social en un solo pago, lo que permitió que los trabajadores que se beneficiaban del monotributo accedieran a las mismas prestaciones de la seguridad social que los trabajadores asalariados, bajo el principio de solidaridad (OIT, 2014b). En la Argentina se ha dado una experiencia similar con el subsidio de las contribuciones a la seguridad social para los trabajadores por cuenta propia y para las microempresas, y en el Brasil el programa SIMPLES de tributación simplificada, diseñado para la micro y pequeña empresa, ha contribuido a reducir de manera significativa los costos de las microempresas en lo que respecta a la seguridad social de los empleados.

A pesar de los avances logrados desde 2002, todavía existe una profunda segmentación en el acceso a la protección social por tipo de empleo y por nivel de ingresos, especialmente en el caso de los planes de pensiones, como se pudo apreciar en el gráfico 2. Mientras que el 66\% y el 55\% de los trabajadores asalariados están afiliados a sistemas de salud y a fondos de pensiones, respectivamente, la cobertura de los trabajadores no asalariados es menor (41\% y 12\%, respectivamente). En 2012, menos del $5 \%$ de los trabajadores no asalariados del quintil más bajo estaba afiliado a un plan de pensiones, frente al $24 \%$ de los trabajadores asalariados del mismo quintil. Incluso en los quintiles más ricos, los trabajadores independientes tienen menos acceso a planes de pensiones o de salud.

Los hogares pobres también tienen menos probabilidades de estar cubiertos por cualquiera de estas protecciones, incluso en aquellos países que cuentan con sistemas integrales, si bien en estos las brechas de cobertura son menos marcadas. Curiosamente, la brecha de cobertura de salud por tipo de empleo es mayor en el segundo quintil que en el más pobre. Esto puede deberse en parte al éxito de los programas de transferencias monetarias condicionadas a la hora de garantizar el acceso a los servicios básicos universales de la población más pobre, dejando de lado a personas que se sitúan justo por encima del umbral. De esta forma, la brecha de cobertura es mayor en el centro de la distribución.

La protección de las personas mayores también ha aumentado en los últimos años. Sin embargo, según los datos de las encuestas de hogares, el mayor incremento se ha producido entre la población más rica. Mientras que en el quintil de ingreso superior el 59\% de las personas mayores tenían acceso a una pensión (contributiva o no contributiva) en 2012, en el quintil más pobre solo el $21 \%$ lo tenían. No solo la cobertura de las pensiones es desigual, también lo es el monto de las prestaciones. Como se muestra en el gráfico 3, los beneficios del quintil más rico de la población son significativamente más altos, incluso en comparación con el cuarto quintil.

Dada la baja cobertura de las pensiones contributivas entre las personas mayores, están surgiendo en la región nuevos planes de pensiones no contributivas bajo el liderazgo del Brasil, Chile y, con una cobertura del 95\%, el Estado Plurinacional de Bolivia. En otros países como México y Panamá, si bien las pensiones no contributivas existen, se trata de subsidios focalizados sujetos a verificación de la condición de pobreza y cubren a menos del 30\% de la población, una proporción que ha aumentado, sin embargo, desde 2002 (CEPAL, 2016).

\footnotetext{
14 Como consecuencia del crecimiento económico, se esperaba que la economía informal desapareciera gradualmente a medida que los trabajadores se fueran desplazando de los sectores más tradicionales (mayoritariamente informales) a sectores más modernos (formales). Véase Kaplan y Levy (2014).
} 


\section{Gráfico 3}

América Latina: cobertura de las pensiones y promedio de pensión mensual de la población de 65 años o más, por quintil de ingreso, alrededor de 2002 y 2012

(En porcentajes y dólares de 2005)

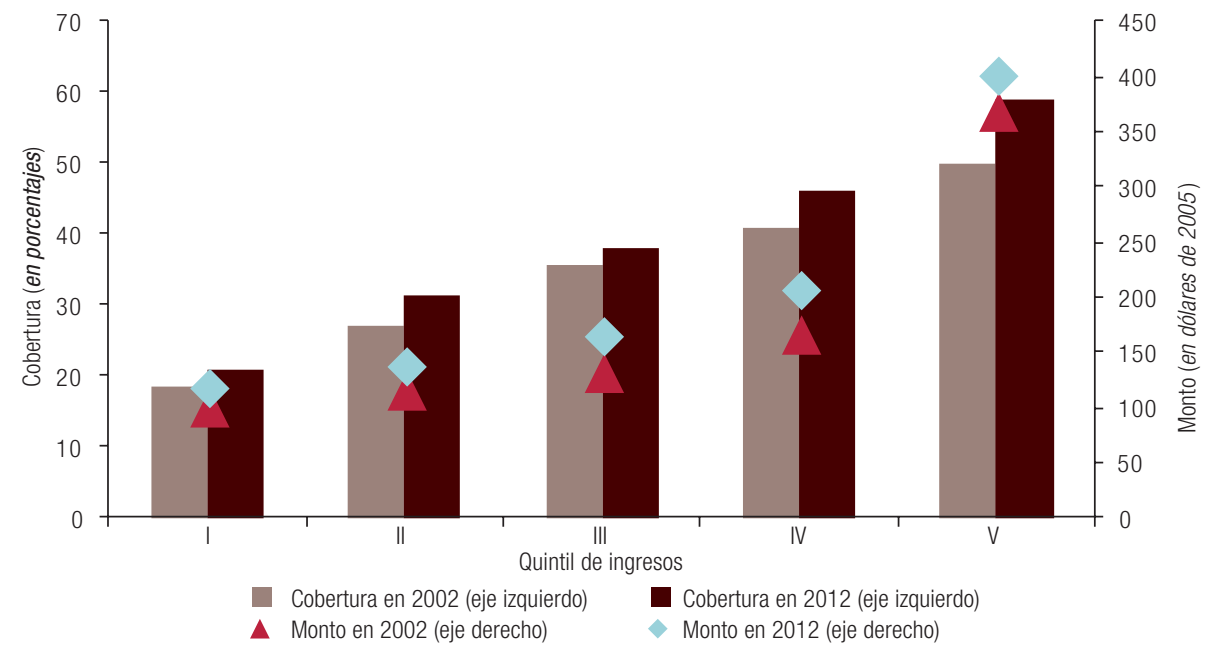

Fuente: Comisión Económica para América Latina y el Caribe (CEPAL), Panorama Social de América Latina 2013 (LC/G.2580), Santiago, 2013; y Desarrollo social inclusivo: una nueva generación de políticas para superar la pobreza y reducir la desigualdad en América Latina y el Caribe (LC/L.4056/Rev.1), Santiago, 2016.

Las acciones emprendidas para ampliar la protección social han ido de la mano de un mayor gasto social: entre 1990 y 2013, este aumentó cerca de 5 puntos porcentuales del PIB. El 70\% de este incremento, impulsado principalmente por la salud y la seguridad social (seguros y asistencia), se produjo entre 2002 y 2013 (véase el gráfico 4). Ahora bien, a pesar de ocupar el segundo lugar en el mundo emergente y en desarrollo en términos de gasto social como porcentaje del PIB, América Latina asigna muchos menos recursos que los países desarrollados a la protección social, ya sea en forma de transferencias directas (que incluyen seguro y asistencia social, pensiones no contributivas y otros beneficios como las asignaciones por hijo) o en salud y educación (véase el gráfico 5).

\section{Gráfico 4}

América Latina: magnitud y composición del gasto público social

(Promedios ponderados por población como porcentaje del PIB)

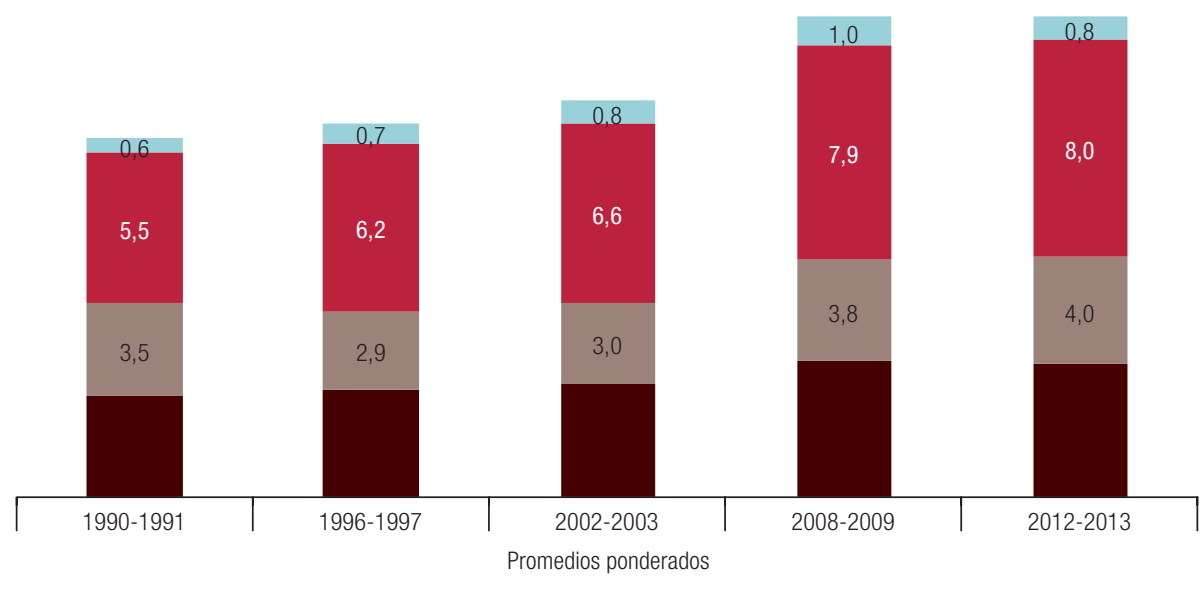

שEducación Galud Vivienda

Fuente: Comisión Económica para América Latina y el Caribe (CEPAL), Panorama Social de América Latina 2013 (LC/G.2580), Santiago, 2013.

Nota: PIB: Producto interno bruto. 


\section{Gráfico 5}

Gasto público social por zonas geográficas

(En porcentajes del PIB)

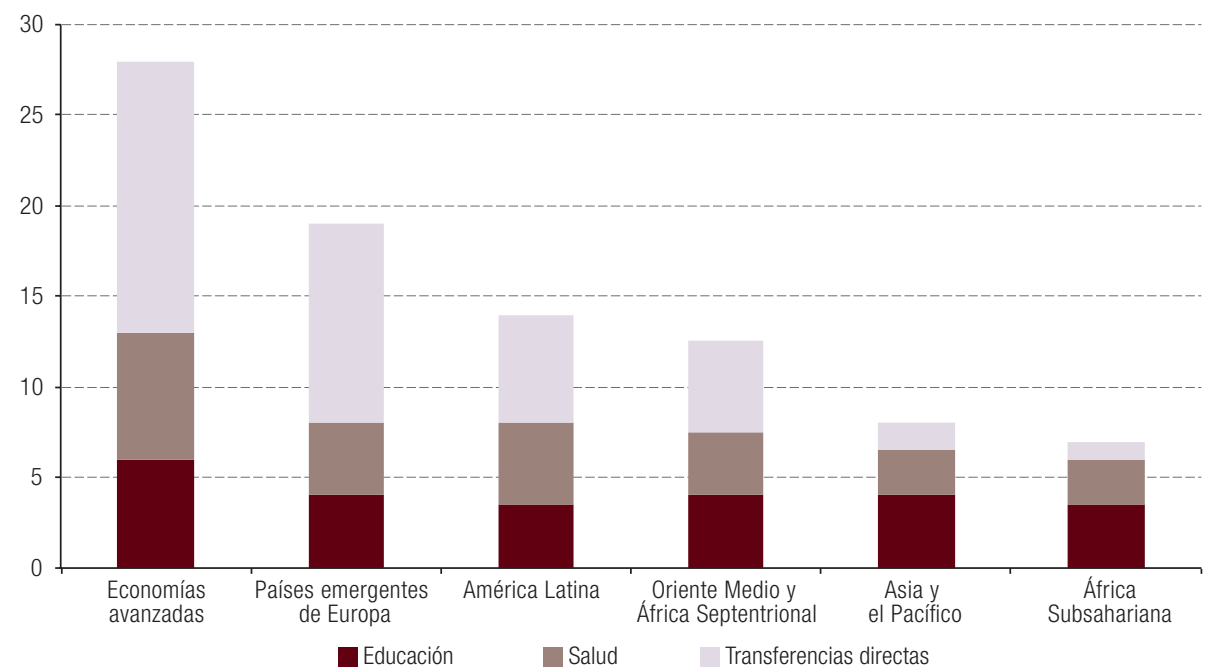

Fuente: F. Bastagli, D. Coady y S. Gupta, "Income inequality and fiscal policy", IMF Staff Discussion Note (SDN/12/08), Washington, D.C., Fondo Monetario Internacional.

Nota: PIB: Producto interno bruto.

Al observar las afiliaciones a los sistemas de salud y de pensiones en las tres categorías de sistemas de protección social definidas en la sección anterior, se extraen dos conclusiones: en primer lugar, los países con sistemas integrales son, en promedio, los que mayor cobertura registran y no presentan segmentaciones importantes por quintil de ingreso o por tipo de empleo en lo que respecta al acceso a la salud, aunque sigue habiendo algunas desigualdades en el acceso a las pensiones; en segundo lugar, las diferencias de cobertura entre las tres categorías de sistemas de protección social son más marcadas en el caso de los trabajadores no asalariados. En los países con sistemas limitados, la mayoría de la población trabajadora no asalariada se encuentra excluida de la protección social, y la seguridad social solo está disponible para una pequeña proporción de trabajadores que tienen un empleo formal, en contraste con los países con sistemas intermedios o integrales, que han avanzado en este sentido. Por ejemplo, mientras que el $80 \%$ y el $46 \%$ de los trabajadores no asalariados de países con sistemas integrales o intermedios, respectivamente, tienen acceso a los sistemas de salud, en los países con sistemas limitados solo un 10\% de ellos cuenta con ese acceso. Esta brecha es mucho mayor que la que afecta a los trabajadores asalariados entre todas las categorías de sistemas de protección social (véase el gráfico 6).

En cualquier caso, todavía queda mucho por hacer. Si bien los programas focalizados han logrado reducir la pobreza, han tenido menos efecto que las prestaciones universales en la disminución de la desigualdad de ingresos (véase la sección V). El siguiente paso debe ir más allá de los estrictos mecanismos focalizados hacia sistemas de protección social más universales, que incluyen la expansión de la seguridad social a medida que los países se desarrollan. Es necesario un sistema de protección social universal que proteja a las personas frente a todo tipo de riesgos, no solo para seguir reduciendo la pobreza, sino también para aumentar la resiliencia de la población que se encuentra por encima de la línea de la pobreza, incluida la clase media (López-Calva y Ortiz-Juárez, 2014; Ferreira y otros, 2013), y generar ciudadanía social. Sin mecanismos de protección universales, los progresos logrados podrían revertirse. Evidentemente, esto también significa que se necesitan más recursos para el gasto social. 


\section{Gráfico 6}

América Latina (países seleccionados)a: afiliación media a sistemas de salud o de pensiones, por categoría del sistema de protección social, en total y en los dos quintiles inferiores, alrededor de 2012

(En porcentajes)

Trabajadores asalariados

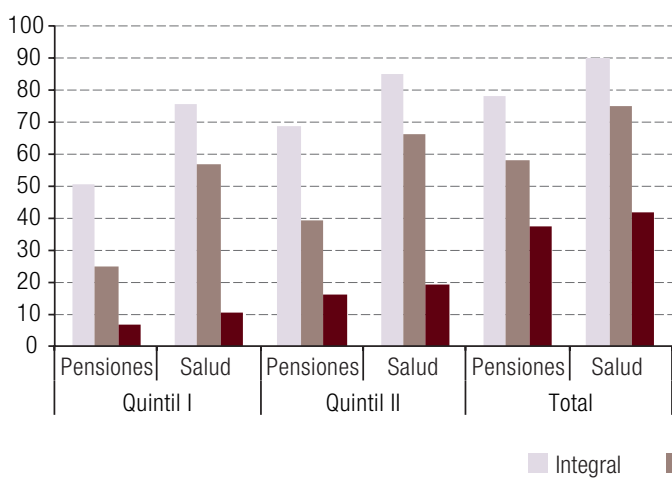

Trabajadores no asalariados

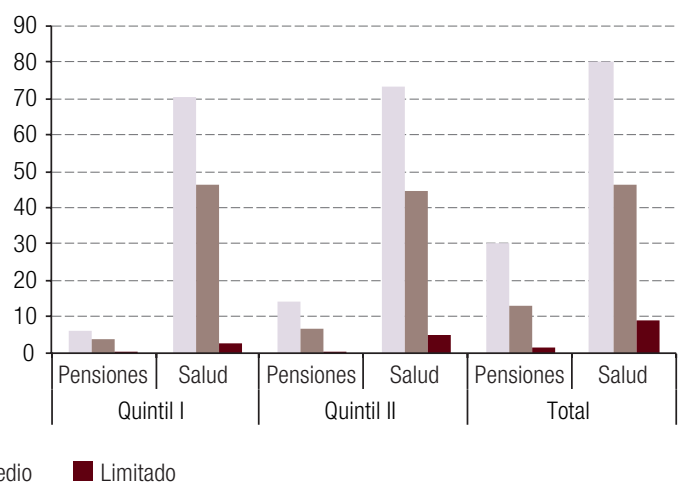

Fuente: Elaboración propia, sobre la base de Comisión Económica para América Latina y el Caribe (CEPAL), Panorama Social de América Latina 2013 (LC/G.2580), Santiago, 2013.

a Los países con sistemas integrales incluyen a la Argentina, Chile, Costa Rica y el Uruguay; los de sistema intermedio incluyen a Colombia, el Ecuador, México, Panamá, el Perú y la República Dominicana, y los de sistemas limitados incluyen a Bolivia (Estado Plurinacional de), El Salvador, Guatemala, Honduras, Nicaragua y el Paraguay.

\section{La eficacia redistributiva del gasto público}

El efecto redistributivo del gasto público varía con las características de los sistemas de protección social. Un mayor gasto social, una cobertura universal y más transferencias progresivas se asocian con un mayor impacto redistributivo.

Usando la información disponible sobre 11 países que proporciona el proyecto Compromiso con la Equidad (CEQ) de la Universidad de Tulane y el Diálogo Interamericano ${ }^{15}$, se puede estimar que, en promedio, los países con datos disponibles que tienen sistemas integrales de protección social reducen la desigualdad 0,021 puntos del coeficiente de Gini a través de transferencias directas, y 0,085 a través de prestaciones en especie. En el caso de los sistemas intermedios, estas reducciones son de 0,010 y 0,037 puntos del coeficiente de Gini, respectivamente, mientras que los países con sistemas limitados casi no tienen incidencia en la desigualdad a través de las transferencias directas $(0,006)$ y logran un efecto redistributivo muy pequeño $(0,030)$ a través de las prestaciones en especie (véase el gráfico 7).

15 El proyecto Compromiso con la Equidad (CEQ) hace un análisis estándar de incidencia para analizar cuánta redistribución y reducción de pobreza se está logrando en cada país a través del gasto social, los subsidios y los impuestos, y cuán progresivos son la recaudación impositiva y el gasto público. El análisis de incidencia mide los cambios en el coeficiente de Gini y el indicador de pobreza bajo diferentes conceptos de ingreso (antes de impuestos y trasferencias, después de impuestos directos y después de transferencias directas y en especie). Todos los documentos de trabajo del proyecto CEQ están recogidos en la bibliografía. 


\section{Gráfico 7}

América Latina (11 países): efecto redistributivo del gasto social en forma de transferencias directas y prestaciones en especie

(Variación absoluta del coeficiente de Gini)

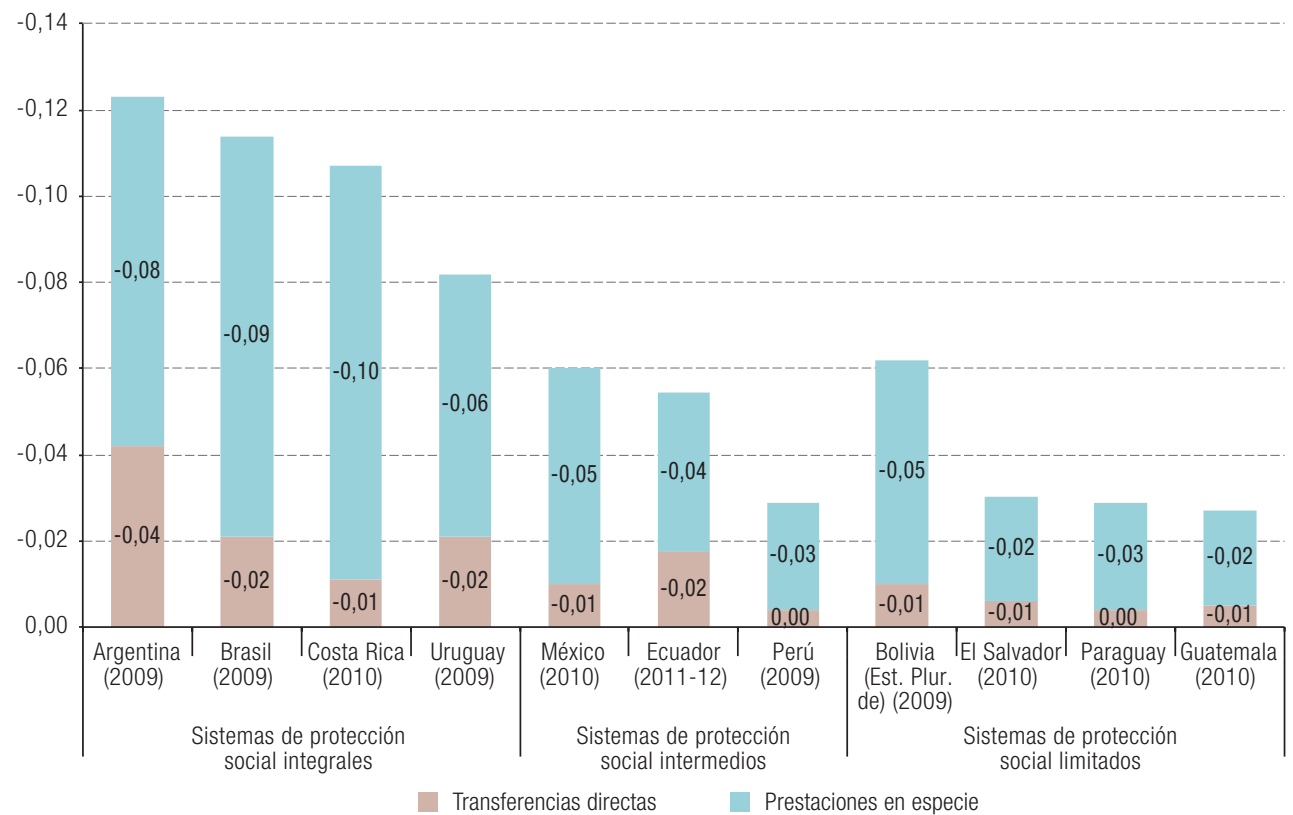

Fuente: Proyecto Compromiso con la Equidad (CEQ), sobre la base de M. Cabrera, N. Lustig y H.E. Morán, "Fiscal policy, inequality, and the ethnic divide in Guatemala", World Development, vol. 76, Amsterdam, Elsevier, 2015; N. Lustig y otros, "The impact of taxes and social spending on inequality and poverty in Argentina, Bolivia, Brazil, Mexico and Peru: A Synthesis of Results", CEQ Working Paper, N 3, CEQ Institute, 2012; N. Lustig, C. Pessino y J. Scott, "The impact of taxes and social spending on inequality and poverty in Argentina, Bolivia, Brazil, Mexico, Peru and Uruguay: an overview", CEQ Working Paper, N 13, CEQ Institute, 2013; J. Sauma y D. Trejos, "Gasto público social, impuestos, redistribución del ingreso y pobreza en Costa Rica", CEQ Working Paper, N 18, CEQ Institute, 2014; M. Beneke, N. Lustig y J.A. Oliva, "El impacto de los impuestos y el gasto social en la desigualdad y la pobreza en El Salvador", CEQ Working Paper, N²6, CEQ Institute, 2015; y F. Llerena y otros, "Social spending, taxes and income redistribution in Ecuador", CEQ Working Paper, № 28, CEQ Institute, 2015.

Nota: Las transferencias en especie incluyen los servicios educativos y de salud, y las transferencias directas incluyen todas las transferencias monetarias como las transferencias condicionadas, los subsidios y las pensiones no contributivas. El efecto redistributivo de las transferencias directas se mide como la diferencia entre el coeficiente de Gini de los ingresos netos de mercado (el ingreso de mercado, incluidas las pensiones contributivas, menos el impuesto sobre la renta personal y las contribuciones del empleado a la seguridad social) y el del ingreso disponible (el ingreso neto de mercado más las transferencias directas). La diferencia entre el ingreso neto de mercado y el ingreso final (que se define como el ingreso disponible más las transferencias en especie y menos los copagos y cargos de uso, e incluye las pensiones) es el efecto de todas las transferencias directas y en especie. Véase una explicación detallada de la metodología en Lustig y Higgins (2013).

Llama la atención que, sea cual sea el tipo de sistema de protección social, el efecto redistributivo de las prestaciones en especie es más significativo que el de las transferencias directas, lo que refleja el mayor presupuesto asignado a este tipo de beneficios y, en la mayoría de los casos, su mayor cobertura. En todos los países, el presupuesto asignado a salud y educación (prestaciones en especie) medido como porcentaje del PIB es más del doble que el dirigido a las transferencias directas (transferencias monetarias condicionadas, subsidios y pensiones no contributivas), y en varios países la diferencia es aún mayor. El presupuesto para las prestaciones en especie varía desde casi el doble del presupuesto de las transferencias directas en el Paraguay (un 6,7\% frente a un 3,5\%) hasta 14 veces mayor en el Perú (el 5,9\% frente al 0,4\%). Las transferencias directas tienden a lograr un mayor impacto en la reducción de la pobreza en países con un sistema de protección social integral. Por ejemplo, en la Argentina, las transferencias directas reducen la incidencia de la pobreza 7,5 puntos porcentuales, en el Ecuador, 3,1 puntos porcentuales y, en el Paraguay, menos de 1 punto porcentual. 
La mayor parte de las diferencias en lo que respecta a la eficacia de los sistemas de protección social responde a las distintas tasas de cobertura, proporción del gasto social y progresividad de las transferencias. Como se aprecia en el gráfico 8, en aquellos países sobre los que el proyecto CEQ ha publicado datos, existe una clara relación entre la magnitud del presupuesto destinado a transferencias sociales y su impacto redistributivo. Cuanto mayor es la proporción de recursos asignados a las transferencias sociales, mayor es su efecto en la redistribución del ingreso: el mayor efecto redistributivo se observa en los cuatro países con sistemas de protección social integrales ${ }^{16}$.

\section{Gráfico 8}

América Latina (11 países): impacto redistributivo del gasto social directo y las transferencias en especie, alrededor de 2010

(En porcentajes)

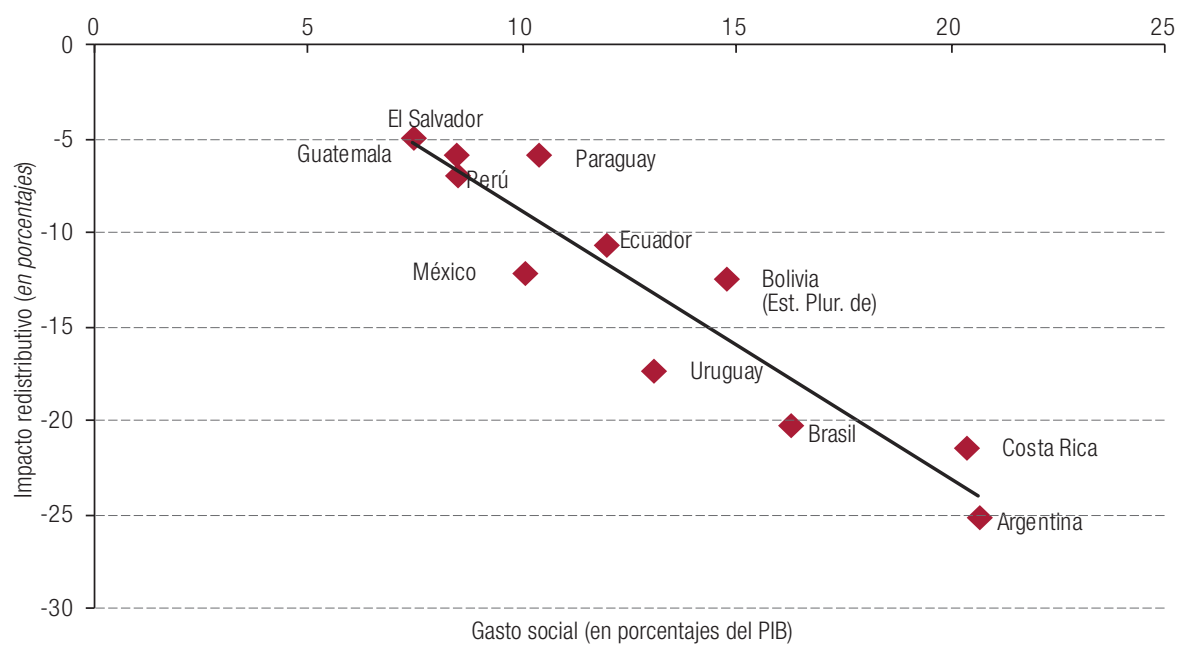

Fuente: Elaboración propia, sobre la base de estudios de los países del proyecto Compromiso con la Equidad (CEQ).

Nota: El impacto redistributivo se calcula restando el coeficiente de Gini del ingreso final al del ingreso neto de mercado, y el resultado se expresa como un porcentaje de este último, para reflejar las diferencias con relación a la desigualdad inicial. PIB: Producto interno bruto.

La progresividad de las transferencias, medida como el porcentaje de prestaciones que llegan a los hogares más pobres, también ilustra las diferencias entre los impactos redistributivos de las transferencias directas o en especie. En el gráfico 9 se muestran los coeficientes de concentración (cuasi-Gini) $^{17}$ de los distintos tipos de gasto social. Mientras que en los países con sistemas integrales todas las transferencias, directas y en especie, son progresivas (excepto en el Brasil, donde las transferencias directas son neutrales), en los países con sistemas limitados solo las transferencias directas son progresivas. Esta progresividad se debe principalmente a los programas de transferencias monetarias condicionadas, que en los países con sistemas limitados representan, en promedio, más del $70 \%$ de las transferencias directas (Higgins y otros, 2013a). En contraste, dada su baja cobertura, las transferencias en especie de estos países son regresivas, como se observa, por ejemplo, en el índice de protección social relativo a la salud.

\footnotetext{
${ }^{16}$ Esta relación también se aplica en el caso de la cobertura. Ocampo (2008) demuestra que cuanto más alta es la puntuación de un país en el índice de desarrollo humano (excluido el ingreso per cápita), mayor será el efecto de las transferencias sociales sobre la distribución del ingreso, es decir, cuanto más universal sea la cobertura de un sistema de protección social, más redistributivo será.

17 El coeficiente cuasi-Gini del gasto social fluctúa entre -1 (una perfecta focalización del gasto en la población pobre) y 1, donde cero representa una situación en la que el gasto se distribuye de manera igualitaria entre todos los grupos sociales.
} 
Gráfico 9

América Latina (10 países): coeficientes de concentración de diferentes tipos de gasto

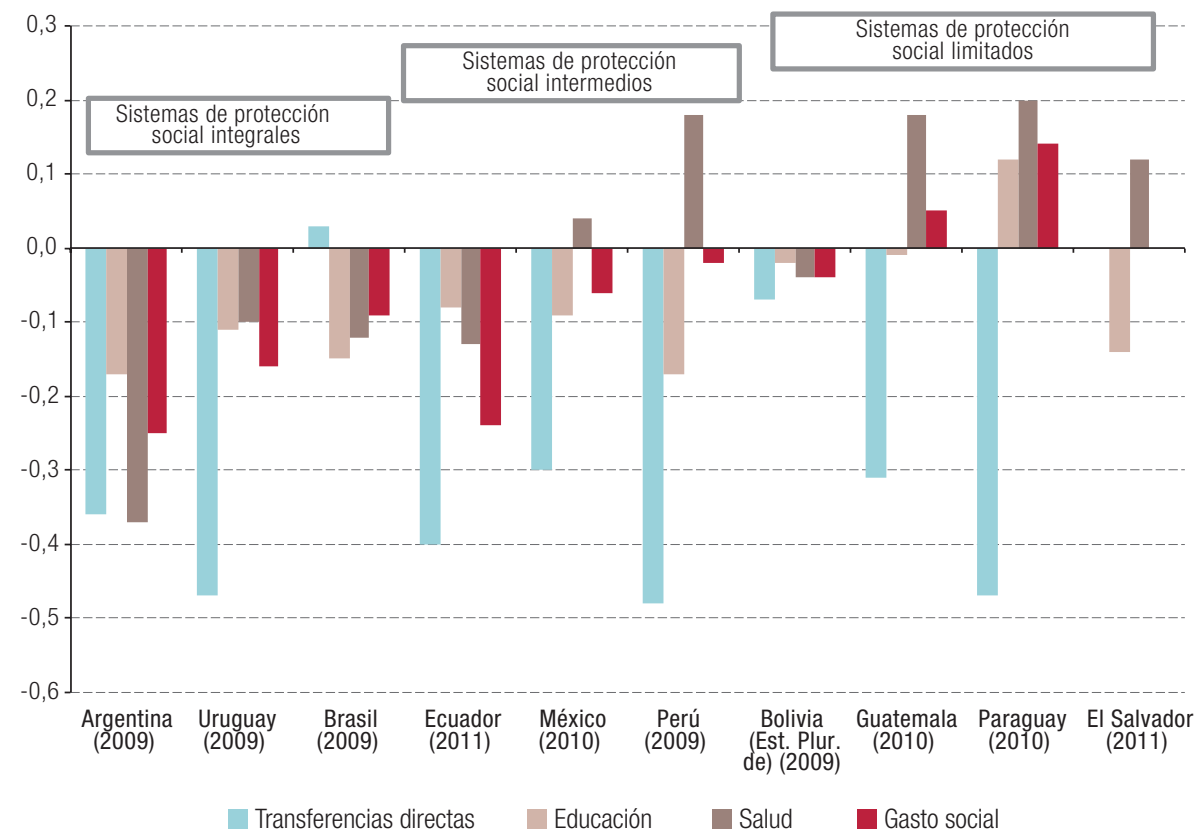

Fuente: Proyecto Compromiso con la Equidad, sobre la base de estudios de los países.

Nota: Los coeficientes de concentración miden cuán progresiva o regresiva es cada transferencia. Un valor inferior a -0,4 significa que la transferencia es progresiva en términos absolutos (más concentrada en los quintiles más bajos), un valor entre $-0,1$ y $-0,4$ significa que la transferencia es moderadamente progresiva; un valor entre $-0,1$ y 0,1 indica que la transferencia es neutra (distribuida de manera uniforme entre los deciles de ingreso), y una transferencia con un valor por encima de 0,1 es regresiva. Entre las transferencias directas se incluyen las pensiones no contributivas o las transferencias monetarias condicionadas.

Con la excepción del Brasil, las transferencias directas son más progresivas que las prestaciones en especie en todos los países. Esto es principalmente producto de los programas de transferencias monetarias condicionadas, que al perseguir la reducción de la pobreza están focalizados en las familias de bajos ingresos, así como de las pensiones no contributivas en aquellos países donde existen. Sin embargo, a pesar de su elevada progresividad, el impacto redistributivo de las transferencias directas es inferior al de las prestaciones en especie, como se mostró en el gráfico 7, dado el menor presupuesto y cobertura de las transferencias directas.

Las prestaciones en especie (servicios de educación y salud) logran el mayor impacto redistributivo cuando son universales, como la educación primaria, y, en la mayoría de los países, la atención de salud (las excepciones se encuentran principalmente en los países con sistemas de protección social limitados, donde esta aún se encuentra vinculada al empleo formal). La educación básica es muy progresiva en todos los casos, se trata de la prestación en especie más universal y concentra una gran proporción del gasto social: esta composición se traduce en un elevado impacto redistributivo. La salud es altamente progresiva en los países con sistemas de protección social integrales, donde la cobertura es universal.

El alto impacto redistributivo de la política social en los países con sistemas de protección social integrales se logra a través de una combinación de gasto social elevado, cobertura universal y prestaciones progresivas. Por el contrario, los países con sistemas limitados gastan menos en transferencias, tanto directas como en especie y, aunque las directas son altamente progresivas, las prestaciones en especie tienen una cobertura limitada (particularmente en la salud), por lo que son regresivas. El resultado es entonces un efecto redistributivo bajo. 
En todo caso, el impacto total de la política fiscal en la región, incluidas las transferencias e impuestos, es todavía muy bajo en comparación con los países más desarrollados. La distribución media de los ingresos de mercado (antes de impuestos y transferencias) de los países de la Organización para la Cooperación y el Desarrollo Económicos (OCDE) y de los 15 miembros más antiguos de la Unión Europea (UE) es similar al promedio de América Latina, pero aquellos países son mucho más eficaces a la hora de reducir la desigualdad. Como resultado de la política fiscal, el coeficiente de Gini se ha reducido, en promedio, un 36\% (17 puntos porcentuales) en los países de la OCDE y 19 puntos porcentuales en los 15 países de la UE, mientras que en América Latina solo ha disminuido un promedio del 6\% (OCDE, 2011; FMI, 2015; Hanni, Martner y Podestá, 2015) ${ }^{18}$. Además, y en contra de los recientes hallazgos de Ostry, Berg y Tsangarides (2014), no está demostrado que los países de América Latina con una distribución más desigual de los ingresos sean los que más redistribuyen, como es el caso de los países de la OCDE. El Uruguay, por ejemplo, tiene una desigualdad relativamente baja en el ingreso de mercado, pero es el país que más redistribuye.

Si bien en la región el gasto fiscal es progresivo y tiene un considerable y creciente impacto redistributivo, los impuestos todavía son, en el mejor de los casos, ligeramente progresivos e incluso regresivos en algunos países, ya que se basan en gran medida en el impuesto sobre el valor agregado (IVA) o impuestos sobre las ventas y relativamente poco en los impuestos sobre la renta personal ${ }^{19}$. De hecho, según un estudio reciente, la combinación de impuestos y transferencias que presentan las políticas fiscales de la región puede hacer que una proporción sustancial de los pobres se vuelvan aún más pobres o que empobrezcan hogares que no lo son (Higgings y Lustig, 2015; Lustig y MartínezAguilar, 2016). En este sentido, sería clave una reforma fiscal que aumente el impuesto sobre la renta y los impuestos progresivos en pro del impacto redistributivo y la eficiencia de la política fiscal.

\section{Mitos sobre la relación entre el crecimiento económico y la redistribución}

Pese a que los sistemas de protección social nacionales de todo el mundo han logrado grandes reducciones de la pobreza y la desigualdad (OIT, 2014a), persiste la duda de si estos resultados se han obtenido a expensas de incurrir en altos costos de oportunidad en términos del crecimiento económico. Una creencia común es que existe una disyuntiva entre el crecimiento y la redistribución. Sin embargo, esta disyuntiva es, en gran parte, un mito. En términos más amplios y de acuerdo con Cichon y Scholz (2009), puede afirmarse que existen tres grandes mitos respecto a la relación entre la protección social y los resultados económicos ${ }^{20}$ :

i) En cada etapa del desarrollo las sociedades solo pueden costear cierto nivel de gasto social (el mito de la asequibilidad);

ii) existe una disyuntiva entre el gasto social (redistribución) y el crecimiento económico (la disyuntiva de Okun).

iii) el crecimiento económico reducirá automáticamente la pobreza (mito de la filtración o goteo).

Un análisis de la experiencia reciente de América Latina permite refutar estos tres mitos. Existe, en primer término, una alta heterogeneidad entre los sistemas de protección social de la región, incluso cuando se tienen en cuenta las diferencias de PIB per cápita; en segundo lugar, no existen datos que demuestren que los países cuyos sistemas de protección social se han expandido más

\footnotetext{
18 Véanse también Goñi, López y Servén (2011) y Lustig, Pessino y Scott (2013).

${ }^{19}$ Véase el proyecto del Woodrow Wilson International Center for Scholars sobre tributación y equidad en América Latina [en línea] https://www.wilsoncenter.org/Publication/Taxation-and-Equality-Latin-America.

20 Véase un análisis de los tres mitos aplicado a los países de la OCDE en Cichon y Scholz (2009).
} 
rápidamente hayan crecido menos, y tercero, existe una correlación más estrecha entre la mejora del índice de protección social y la reducción de la pobreza que entre el crecimiento económico y la reducción de la pobreza.

Como se aprecia en el gráfico 10, aunque existe una asociación positiva entre un mayor PIB per cápita y un valor más alto del índice de protección social ${ }^{21}$, se observa una gran variación en los valores del índice de protección social por nivel de PIB per cápita. Esto queda patente al comparar Costa Rica con Panamá o el Uruguay con México. Costa Rica, con un PIB per cápita solo ligeramente superior a la media regional, tiene la segunda puntuación más alta en el índice de protección social. Desde 1941, el país ha convertido la cobertura universal, tanto en la salud como en las pensiones, en un pilar básico de su estado de bienestar, y siempre ha destacado en los indicadores de inclusión social, a pesar de un PIB per cápita relativamente bajo. Por el contrario, Panamá tiene un PIB per cápita mayor, pero tanto su gasto social como su puntuación en el índice de protección social son relativamente bajos. Lo mismo sucede cuando se compara el Uruguay con México. Pese a tener el segundo PIB per cápita más alto de la región, México tiene un sistema de protección social de categoría intermedia aún más limitado que el de muchos países con PIB per cápita más bajo.

\section{Gráfico 10}

América Latina (18 países): PIB per cápita e índice de protección social, alrededor de 2012

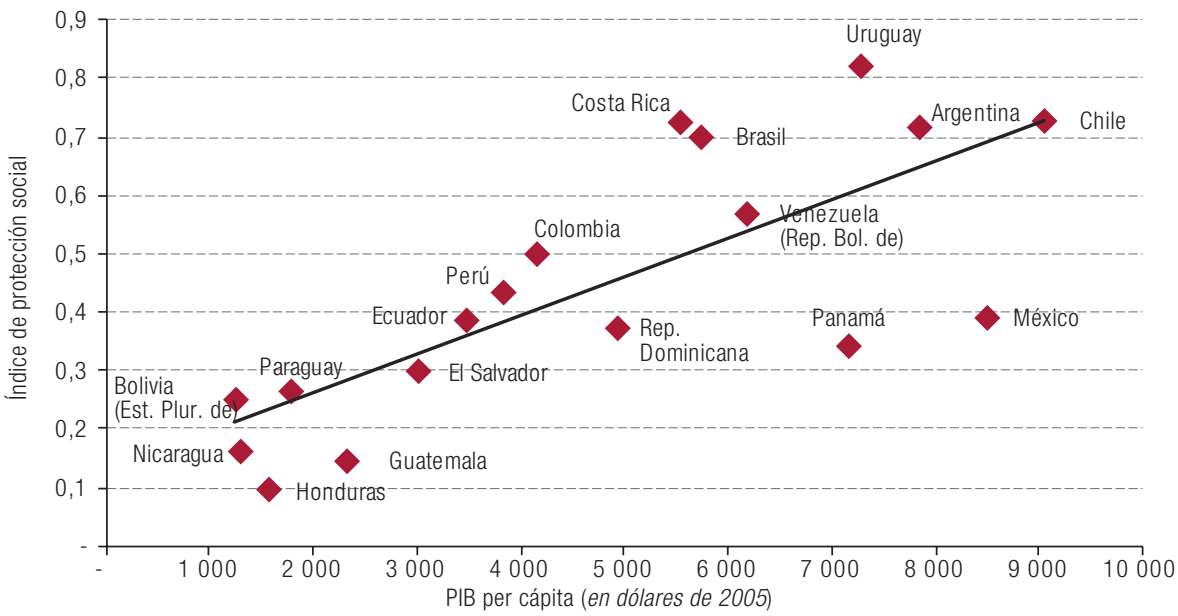

Fuente: Elaboración propia, sobre la base de datos de la Comisión Económica para América Latina y el Caribe (CEPAL). Nota: PIB: Producto interno bruto.

Por lo tanto, no es cierto que el nivel del PIB determine lo que los países pueden permitirse gastar en materia de protección social. De hecho, teniendo en cuenta lo que se tarda en crear un sistema de protección social que funcione correctamente, no es eficiente esperar hasta que se hayan logrado niveles altos de PIB para introducir sistemas de protección integral (Cichon y Scholz, 2009).

En el gráfico 11 se muestra la evolución del índice de protección social y la tasa media de crecimiento anual del PIB per cápita entre 2002 y 2012. Como puede observarse, no existe una asociación negativa entre la mejora del índice de protección social y el crecimiento económico. Por el contrario, la correlación entre ambas variables es cercana a cero $(-0,007)$. De hecho, el Perú, la República Dominicana y Colombia, los tres países donde más aumentó la puntuación del índice de protección social, crecieron a un ritmo mayor que el promedio de América Latina durante el período analizado. No se detecta, por tanto, una disyuntiva entre la expansión del sistema de protección social y el crecimiento económico.

21 Los resultados relativos a los mitos 1 y 2 se mantienen, aunque solo se relacionen con el porcentaje de gasto social. 


\section{Gráfico 11}

América Latina (18 países): tasa de crecimiento medio anual del PIB per cápita y evolución del índice de protección social, 2002-2012

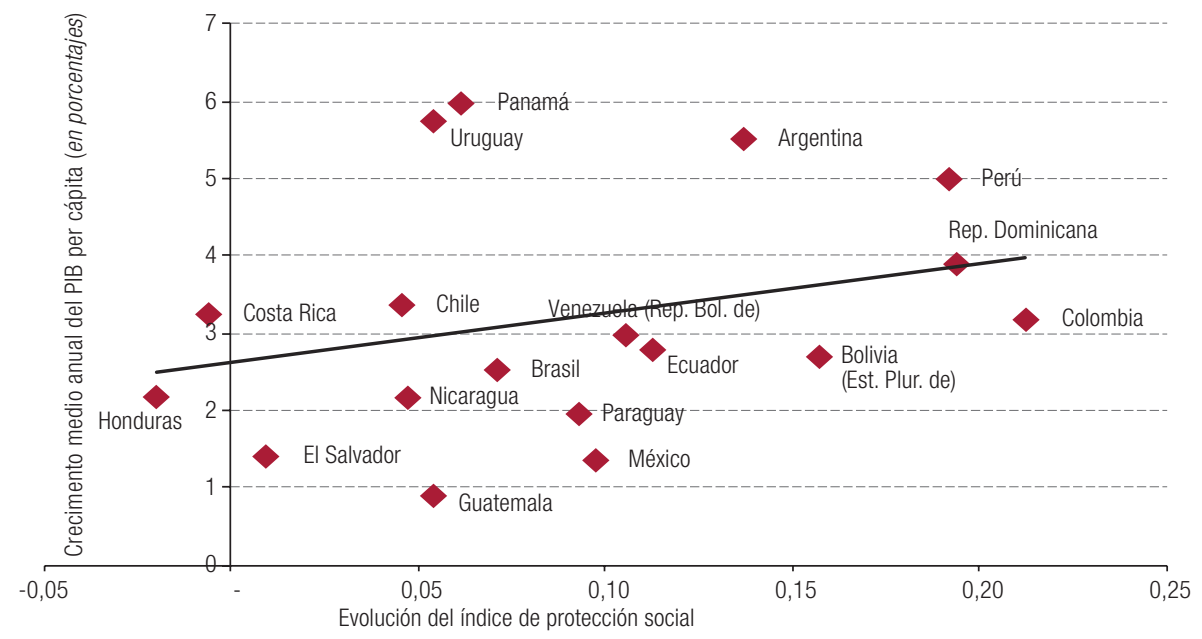

Fuente: Elaboración propia, sobre la base de datos de la Comisión Económica para América Latina y el Caribe (CEPAL). Nota: PIB: Producto interno bruto.

Esta conclusión coincide con estudios recientes del Fondo Monetario Internacional (FMI) que no han encontrado indicios de que la redistribución tenga efectos negativos sobre el crecimiento económico. Según uno de estos estudios, el impacto de la redistribución sobre el crecimiento parece ser benigno en general; solo en casos extremos existe algún indicio de que pueda tener efectos negativos directos sobre el crecimiento (Ostry, Berg y Tsangarides, 2014, pág. 2). Esto significa que, en general, la combinación de los efectos directos e indirectos de la redistribución (incluidos los efectos de la menor desigualdad resultante sobre el crecimiento) favorece el crecimiento. Esto conlleva, por supuesto, fuertes implicaciones para las políticas públicas.

Finalmente, el último mito sostiene que el crecimiento económico reduce automáticamente la pobreza. La incidencia de la pobreza ha disminuido drásticamente en América Latina entre 2003 y 2013: mientras que, a principios de la década de 2000, el 43\% de la población de la región vivía en la pobreza, según datos de la CEPAL, en 2013 dicha tasa se había reducido a solo el 28\%. La rápida reducción de la pobreza se basó en una combinación de crecimiento económico acelerado y de redistribución. El crecimiento económico fue especialmente favorable para los pobres, dado que los ingresos de los deciles más bajos aumentaron más rápido que los ingresos de los deciles más altos. Además, este crecimiento más acelerado se tradujo en un aumento del empleo formal. En cuanto a la redistribución, el mayor gasto social tuvo notables efectos, y redujo tanto la pobreza como la desigualdad (Lustig, López-Calva y Ortiz-Juárez, 2013)²2.

Como se muestra en el gráfico 12, la pobreza se reduce tanto cuando aumenta el índice de protección social como cuando se incrementa el PIB per cápita. Sin embargo, cabe destacar que en América Latina la correlación parece haber sido mayor con la evolución del índice de protección social (izquierda) que con la tasa de crecimiento anual del PIB per cápita (derecha) ${ }^{23}$. Esto indica que la reducción de la pobreza está más asociada a la alta puntuación en el índice de protección social que a las tasas de crecimiento del PIB.

\footnotetext{
22 Ver Cecchini (2014) y Fiszbein y otros (2009).

23 Incluso al realizar unas regresiones simples, se observa que el $\mathrm{R}^{2}$ del índice de protección social es más alto y más significativo que el del PIB per cápita.
} 


\section{Gráfico 12}

América Latina (16 países): evolución de la incidencia de la pobreza según los cambios del índice de protección social y de la tasa media de crecimiento del PIB per cápita, 2002-2012
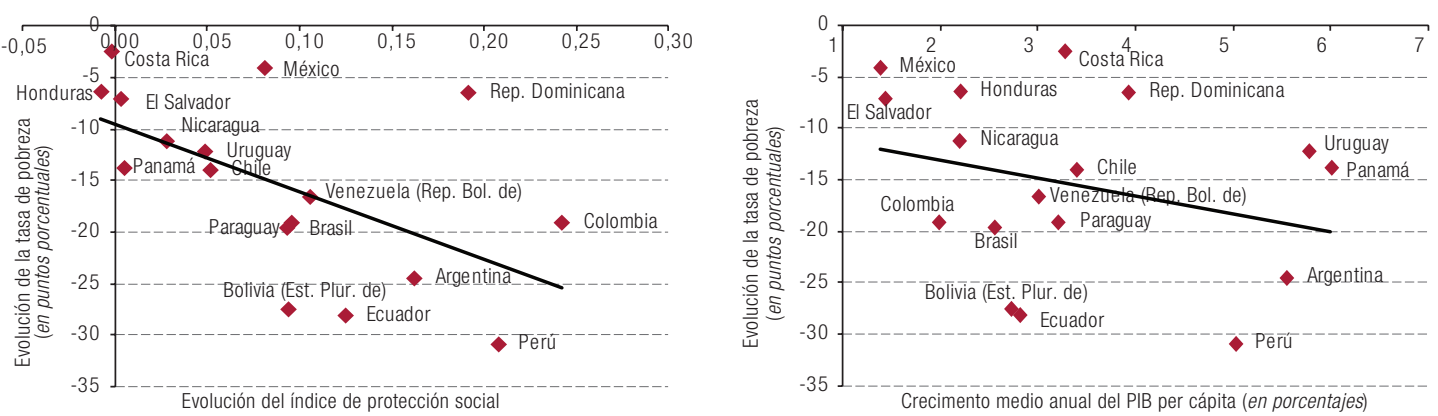

Fuente: Elaboración propia, sobre la base de datos de la Comisión Económica para América Latina y el Caribe (CEPAL).

Nota: PIB: Producto interno bruto.

Un análisis de regresión lineal de la variación absoluta de la tasa de pobreza (en puntos porcentuales) entre 2002 y 2012 en función del crecimiento anual medio del PIB per cápita y de la variación absoluta del índice de protección social controlando el nivel de desigualdad muestra que la variación de la pobreza está asociada de forma significativa y positiva con ambas variables (véase el cuadro 2) ${ }^{24}$. Sin embargo, cuando se analiza el coeficiente estandarizado beta, que representa el cambio de la tasa de pobreza generado por un cambio equivalente a una desviación estándar de la variable explicativa, se observa que una desviación estándar en el índice de protección social tiene un efecto más fuerte en la reducción de la pobreza que un cambio de esta magnitud en el PIB per cápita (modelos 3 y 4). La estabilidad de los coeficientes estimados tanto en el caso del crecimiento del PIB como del índice de protección social muestra que son robustos.

Una especificación del modelo analiza la variación de la tasa de pobreza como función del crecimiento del PIB y del gasto social (sin incluir el índice de protección social). Curiosamente, se observa que durante el período analizado un mayor gasto social no tiene, per se, una asociación significativa con la reducción de la pobreza (véase la regresión que se reproduce en la columna 5 del cuadro 2). Por otro lado, se calculó un índice de protección social ajustado que no incluía la dimensión del gasto social, pero sí los indicadores de cobertura (las dimensiones de universalidad y solidaridad). Como se observa en la regresión que se reproduce en la columna 6 del cuadro 2, aunque el gasto social no tenga un efecto significativo en la reducción de la pobreza, una mejora del índice de protección social ajustado (sin el gasto social) sí lo tiene; esto podría indicar que el gasto social por sí solo no está necesariamente asociado a la reducción de la pobreza, a menos que vaya acompañado de una ampliación de la cobertura de los servicios sociales. El aumento de una desviación estándar del índice de protección social ajustado también tiene un efecto mayor que el mismo aumento del PIB per cápita, como se evidencia en las columnas 3 y 4 del cuadro 2.

\footnotetext{
${ }^{24}$ La inclusión de la variable de dependencia demográfica no dio ningún resultado estadísticamente significativo. Por este motivo y por los limitados grados de libertad con que se contaba, se excluyeron dichos resultados del cuadro.
} 
Cuadro 2

Análisis de regresión

\begin{tabular}{|c|c|c|c|c|c|c|}
\hline \multirow{2}{*}{ VARIABLES } & (1) & (2) & (3) & (4) & (5) & (6) \\
\hline & Modelo 1 & Modelo 2 & Modelo 3 & Modelo 4 & Modelo 5 & Modelo 6 \\
\hline \multirow[t]{2}{*}{ Cambio del índice de protección social } & & $-1,384^{\star \star}$ & $-1,392^{\star \star}$ & $-1,196^{\star \star}$ & & \\
\hline & & $(-0,464)$ & $(-0,466)$ & $(-0,401)$ & & \\
\hline \multirow[t]{2}{*}{ Crecimiento del PIB per cápita } & $-2,332^{*}$ & & $-2,353^{\star *}$ & $-1,951^{\star \star}$ & $-2,062^{*}$ & $-1,213$ \\
\hline & $(-0,372)$ & & $(-0,375)$ & $(-0,311)$ & $(-0,329)$ & $(-0,193)$ \\
\hline \multirow[t]{2}{*}{ Cambio del coeficiente de Gini } & & & & $1,022^{* \star *}$ & $1,178^{\star * *}$ & $1,039^{\star \star \star}$ \\
\hline & & & & $(0,555)$ & $(0,640)$ & $(0,564)$ \\
\hline \multirow[t]{2}{*}{ Cambio del gasto social } & & & & & $-0,072$ & $-0,014$ \\
\hline & & & & & $(-0,229)$ & $(-0,045)$ \\
\hline \multirow[t]{2}{*}{ Cambio del índice de protección social ajustado } & & & & & & $-0,432^{\star \star *}$ \\
\hline & & & & & & $(-0,463)$ \\
\hline Constante & $-0,081^{\star *}$ & $-0,105^{\star \star \star}$ & $-0,037$ & $-0,006$ & 0,054 & $-0,006$ \\
\hline Observaciones & 18 & 18 & 18 & 18 & 18 & 18 \\
\hline $\mathrm{R}^{2}$ & 0,138 & 0,215 & 0,356 & 0,655 & 0,547 & 0,712 \\
\hline
\end{tabular}

Fuente: Elaboración propia.

Nota: Entre paréntesis, coeficientes beta normalizados.

${ }^{\star \star \star} p<0,01,{ }^{\star \star} p<0,05,{ }^{\star} p<0,1$. PIB: Producto interno bruto.

Estos resultados no deben interpretarse como una elección entre transferencias sociales o crecimiento económico a la hora de reducir la pobreza, sino más bien como una prueba de la fuerte complementariedad de estos dos factores. Sin mecanismos redistributivos bien diseñados como los sistemas de protección social integrales, el crecimiento económico puede no tener grandes efectos sobre la pobreza, y puede que los efectos que tenga no sean automáticos ${ }^{25}$.

Dadas las proyecciones de menor crecimiento económico en el futuro próximo en la región, la mejor estrategia para reducir la pobreza y para continuar con las tendencias sociales positivas del período comprendido entre 2003 y 2013 puede ser proseguir con la expansión de los sistemas de protección social y su cobertura universal.

\section{Conclusiones}

En la mayoría de los países de América Latina todavía existen altos niveles de informalidad en el mercado de trabajo, un exiguo nivel de contribuciones obligatorias a la seguridad social, una protección social contributiva de limitada cobertura y una política fiscal con un bajo impacto redistributivo, por lo que los retos de la protección y la política social son considerables en una época de lento crecimiento económico. Se necesitan nuevas soluciones, tanto para las transferencias como para los impuestos. Se debería avanzar hacia prestaciones universales y una ampliación de los mecanismos de protección social no contributivos, a la vez que hacia la formalización laboral y el desarrollo de mecanismos flexibles que aumenten las prestaciones y contribuciones de la seguridad social. La creciente clase media trae nuevas demandas de protección social, y no bastará con más de lo mismo: se requieren más recursos (tanto contribuciones como impuestos) y una cobertura universal (con una combinación de regímenes contributivos y no contributivos). Los programas de asistencia social focalizados en los que se ha centrado la atención en las últimas décadas ya no son suficientes.

25 Cichon y Scholz (2009) llegan a la misma conclusión en un análisis similar sobre otros países. 
La cobertura universal de los servicios sociales debe ser el objetivo esencial de la política social y es el mejor instrumento para aumentar el impacto redistributivo del gasto social. Las prestaciones universales resultarán más eficaces a la hora de reducir la desigualdad de ingresos y crear sociedades más equitativas. La causalidad funciona en ambos sentidos: las sociedades más igualitarias exigen sistemas universales de protección social y política social, y estos, a su vez, contribuyen a la igualdad. Las políticas universales tienen también una ventaja política, particularmente de cara a la clase media, lo que es esencial para lograr el apoyo político que precisa el sector público a la hora de obtener los recursos necesarios que permitirán poner en práctica las políticas universales.

El diseño del régimen tributario supone, por tanto, un importante desafío. En el centro de este desafío se sitúa la escasa recaudación tributaria de América Latina, particularmente en concepto de impuestos sobre la renta personal, y su combinación con el bajo nivel de las transferencias, como han señalado ampliamente la CEPAL, el Banco Mundial y el FMI (véase, por ejemplo, FMI, 2014 y 2015). La capacidad de subir los impuestos, particularmente los más redistributivos, para desarrollar sistemas universales de gasto social es el terreno donde se librará la batalla por la equidad en los años venideros.

\section{Bibliografía}

Angulo, R. y N. Gómez (2015), "Inclusión social e inclusión productiva de los beneficiarios del programa Más Familias en Acción: estudio de caso de Colombia" [en línea] http://dds.cepal.org/redesoc/archivos_ recursos/4371/Roberto-Angulo_2014_Colombia.pdf.

Barrientos, A. (2011), "On the distributional implications of social protection reforms in Latin America", Documento de Trabajo, № 2011/69, Helsinki, Instituto Mundial de Investigaciones de Economía del Desarrollo (UNU-WIDER).

Bastagli, F., D. Coady y S. Gupta (2012), "Income inequality and fiscal policy", IMF Staff Discussion Note, SDN/12/08, Washington, D.C., Fondo Monetario Internacional.

Beneke, M., N. Lustig y J.A. Oliva (2015), "El impacto de los impuestos y el gasto social en la desigualdad y la pobreza en El Salvador", CEQ Working Paper, № 26, CEQ Institute.

Bértola, L. y J.A. Ocampo (2013), El desarrollo económico de América Latina desde la independencia, Ciudad de México, Fondo de Cultura Económica.

Cabrera, M., N. Lustig y H.E. Morán (2015), "Fiscal policy, inequality, and the ethnic divide in Guatemala", World Development, vol. 76, Amsterdam, Elsevier.

Cecchini, S. (2014), "Social protection, poverty and inequality: a comparative perspective", Journal of Southeast Asian Economies, vol. 31, N 1.

Cecchini, S. y R. Martínez (2012), "Protección social inclusiva en América Latina: una mirada integral, un enfoque de derechos", Libros de la CEPAL, № 111 (LC/G.2488-P), Santiago, Comisión Económica para América Latina y el Caribe (CEPAL).

CEPAL (Comisión Económica para América Latina y el Caribe) (2016), Desarrollo social inclusivo: una nueva generación de políticas para superar la pobreza y reducir la desigualdad en América Latina y el Caribe (LC/L.4056/Rev.1), Santiago.

(2014a), Pactos para la igualdad: hacia un futuro sostenible (LC/G.2586(SES.35/3)), Santiago.

(2014b), Panorama Social de América Latina 2014 (LC/G.2635-P), Santiago.

(2013), Panorama Social de América Latina 2013 (LC/G.2580), Santiago.

(2000), Equidad, desarrollo y ciudadanía (LC/G.2071/Rev.1-P), Santiago.

Cichon, M. y W. Scholz (2009), "Social security social impact and economic performance: a farewell to the three famous myths", Building Decent Societies: Rethinking the Role of Social Security in State Building, P. Townsend (ed.), Londres, Palgrave Macmillan.

Ferreira, F. y otros (2013), Economic Mobility and the Rise of the Latin American Middle Class, Washington, D.C., Banco Mundial.

Ferreira, F. y D. Robalino (2011), "Social assistance in Latin America: achievements and limitations", Handbook of Latin American Economics, J.A. Ocampo y J. Ros (eds.), Oxford, Oxford University Press. 
Filgueira, F. y otros (2006), "Universalismo básico: una alternativa posible y necesaria para mejorar las condiciones de vida", Universalismo básico: una nueva política social para América Latina, C. Molina (ed.), Washington, D.C., Banco Interamericano de Desarrollo.

Fiszbein, A. y otros (2009), "Transferencias monetarias condicionadas: reducción de la pobreza actual y futura", Washington, D.C., Banco Mundial [en línea] https://openknowledge.worldbank.org/handle/10986/2597.

FMI (Fondo Monetario Internacional) (2015), Perspectivas de la economía mundial. Crecimiento dispar: factores a corto y largo plazo, Washington, D.C. (2014), "Fiscal policy and income inequality", IMF Policy Paper, Washington D.C.

Goñi, E., H. López y L. Servén (2011), "Fiscal redistribution and income inequality in Latin America”, World Development, vol. 39, № 9, Amsterdam, Elsevier.

Hanni, M., R. Martner y A. Podestá (2015), "El potencial redistributivo de la fiscalidad en América Latina", Revista CEPAL, N 116 (LC/G.2643-P), Santiago, Comisión Económica para América Latina y el Caribe (CEPAL).

Higgins, S. y N. Lustig (2015), "Can a poverty-reducing and progressive tax and transfer system hurt the poor?", CGD Working Paper, N 405, Washington, D.C., Center for Global Development [en línea] http://www.cgdev.org/publication/can-poverty-reducing-and-progressive-tax-and-transfer-systemhurtpoor\%03-working-paper.

Higgins, S. y otros (2013a), "Social spending, taxes and income redistribution in Paraguay", CEQ Working Paper, N¹1, CEQ Institute.

_ (2013b), "Comparing the incidence of taxes and social spending in Brazil and the United States", CEQ Working Paper, N 16, CEQ Insitute.

Kaplan, D. y S. Levy (2014), "The evolution of social security systems in Latin America", Social Insurance, Informality, and Labor Markets: How to Protect Workers while Creating Good Jobs, M. Frolich y otros (eds.), Nueva York, Oxford University Press.

Korpi, W. y J. Palme (1998), "The paradox of redistribution and strategies of equality: welfare state institutions, inequality and poverty in the Western countries", American Sociological Review, vol. 63, N 5.

Llerena, F. y otros (2015), "Social spending, taxes and income redistribution in Ecuador", CEQ Working Paper, N²8, CEQ Institute.

López-Calva, L.F. y E. Ortiz-Juárez (2014), "A vulnerability approach to the definition of the middle class", Journal of Economic Inequality, vol. 12, N 1, Springer.

Lustig, N. y S. Higgins (2013), "Commitment to Equity Project: estimating the incidence of social spending, subsidies and taxes. Handbook", CEQ Working Paper, N 1, CEQ Institute.

Lustig, N., L.F. López-Calva y E. Ortiz-Juárez (2013), "Deconstructing the decline in inequality in Latin America", Policy Research Working Paper, N 6552, Washington, D.C., Banco Mundial.

Lustig, N. y otros (2012), "The impact of taxes and social spending on inequality and poverty in Argentina, Bolivia, Brazil, Mexico and Peru: a synthesis of results", CEQ Working Paper, N 3, CEQ Institute.

Lustig, N. y C. Pessino (2013), "Social spending and income redistribution in Argentina in the 2000s: the rising role of noncontributory pensions", CEQ Working Paper, N5, CEQ Institute.

Lustig, N., C. Pessino y J. Scott (2013), "The impact of taxes and social spending on inequality and poverty in Argentina, Bolivia, Brazil, Mexico, Peru and Uruguay: an overview”, CEQ Working Paper, N 13, CEQ Institute.

Lustig, N. y S. Martínez-Aguilar (2016), "Winners and losers: the impact of fiscal policy on the poor and vulnerable in Latin America", inédito.

Marshall, T.H. (1992), "Citizenship and social class", Citizenship and Social Class, T.H. Marshall y T. Bottomore, Londres, Pluto Press.

Montenegro, F. y O. Acevedo (2013), "Colombia case study: the subsidized regime of Colombia's national health insurance system", Universal Health Coverage (UNICO) Studies Series, N 15, Washington, D.C., Banco Mundial.

Ocampo, J.A. (2008), "Las concepciones de la política social: universalismo versus focalización", Nueva Sociedad, $N^{\circ} 215$.

(2007), "Market, social cohesion, and democracy", Policy Matters: Economic and Social Policies to Sustain Equitable Development, José Antonio Ocampo, Jomo Kwame Sundaram y Sarbuland Khan (eds.), Orient Longman.

Ocampo, J.A. y N. Gómez-Arteaga (2016), "Sistemas de protección social en América Latina: una evaluación", Documento de Trabajo, № 52, Ginebra, Organización Internacional del Trabajo (OIT). 
OCDE (Organización para la Cooperación y el Desarrollo Económicos) (2011), Divided We Stand: Why Inequality Keeps Rising, París.

OIT (Organización Internacional del Trabajo) (2014a), World Social Protection Report, Ginebra.

_ (2014b), "Monotax: promoting formalization and protection of independent workers", Policy Brief, N 02/2014.

_ (2012), Social Security for All: Building Social Protection Floors and Comprehensive Social Security Systems. The Strategy of the International Labour Organization, Ginebra.

_(2008), Declaración de la OIT sobre la Justicia Social para una Globalización Equitativa, Ginebra.

Ostry, J., A. Berg y Ch. Tsangarides (2014), "Redistribution, inequality, and growth", IMF Staff Discussion Note, SDN/14/02, Washington, D.C., Fondo Monetario Internacional.

PNUD (Programa de las Naciones Unidas para el Desarrollo) (2004), La democracia en América Latina. Hacia una democracia de ciudadanas y ciudadanos, Buenos Aires, Aguilar, Altea, Taurus, Alfaguara.

Santos, M.E. y otros (2015), "A multidimensional poverty index for Latin America", OPHI Working Paper, $N^{\circ} 79$, Universidad de Oxford.

Sauma, J. y D. Trejos (2014), "Gasto público social, impuestos, redistribución del ingreso y pobreza en Costa Rica”, CEQ Working Paper, № 18, CEQ Institute.

Sen, A. (2000), Desarrollo y libertad, Buenos Aires, Planeta.

Williamson, J. (1990), "What Washington means by policy reform", Latin American Adjustment. How Much Has Happened?, John Williamson (ed.), Washington, D.C., Instituto de Economía Internacional. 


\section{Anexo A1}

Cuadro A1.1

Indicadores utilizados para construir el índice de protección social

\begin{tabular}{|c|c|c|c|c|c|}
\hline Dimensión & Indicador & Medida & $\begin{array}{c}\text { Referente } \\
\text { máximo (meta) } \\
\text { (en porcentajes) }\end{array}$ & $\begin{array}{l}\text { Referente mínimo } \\
\text { (en porcentajes) }\end{array}$ & Fuente de datos \\
\hline \multirow[t]{5}{*}{ Universalidad } & $\begin{array}{l}\text { Acceso a la } \\
\text { atención de salud } \\
\text { entre los ocupados }\end{array}$ & $\begin{array}{l}\text { Proporción de trabajadores } \\
\text { asalariados con acceso a } \\
\text { la atención de salud }\end{array}$ & 100 & 28,80 & $\begin{array}{l}\text { Panorama social de } \\
\text { América Latina } 2013 \\
\text { (CEPAL, 2013) }\end{array}$ \\
\hline & $\begin{array}{l}\text { Acceso a pensiones } \\
\text { entre los ocupados }\end{array}$ & $\begin{array}{l}\text { Proporción de trabajadores } \\
\text { asalariados afiliados a un } \\
\text { sistema de pensiones }\end{array}$ & 100 & 26,30 & $\begin{array}{l}\text { Panorama social de } \\
\text { América Latina } 2013 \\
\text { (CEPAL, 2013) }\end{array}$ \\
\hline & $\begin{array}{l}\text { Población mayor } \\
\text { que recibe una } \\
\text { pensión }\end{array}$ & $\begin{array}{l}\text { Proporción de personas } \\
\text { mayores ( } 65 \text { años o más) } \\
\text { que reciben una pensión }\end{array}$ & 100 & 5,70 & $\begin{array}{l}\text { Panorama social de } \\
\text { América Latina } 2013 \\
\text { (CEPAL, 2013) }\end{array}$ \\
\hline & $\begin{array}{l}\text { Brecha de } \\
\text { cobertura en } \\
\text { el acceso a la } \\
\text { atención de salud } \\
\text { por tipo de empleo }\end{array}$ & $\begin{array}{l}\text { Brecha de cobertura en el acceso a } \\
\text { la atención de salud (trabajadores } \\
\text { asalariados cubiertos menos } \\
\text { los no asalariados cubiertos } \\
\text { como porcentaje del total de los } \\
\text { trabajadores de cada grupo) }\end{array}$ & 0 & -97 & $\begin{array}{l}\text { Panorama social de } \\
\text { América Latina } 2013 \\
\text { (CEPAL, 2013) }\end{array}$ \\
\hline & $\begin{array}{l}\text { Brecha de } \\
\text { cobertura en } \\
\text { la afiliación a } \\
\text { un sistema de } \\
\text { pensiones por } \\
\text { tipo de empleo }\end{array}$ & $\begin{array}{l}\text { Brecha de cobertura en la afiliación } \\
\text { a un sistema de pensiones } \\
\text { (trabajadores asalariados afiliados } \\
\text { menos los no asalariados afiliados } \\
\text { como porcentaje del total de los } \\
\text { trabajadores de cada grupo) }\end{array}$ & 0 & -98 & $\begin{array}{l}\text { Panorama social de } \\
\text { América Latina } 2013 \\
\text { (CEPAL, 2013) }\end{array}$ \\
\hline Solidaridad & $\begin{array}{l}\text { Cobertura en el } \\
\text { quintil más pobre } \\
\text { (todo tipo de } \\
\text { asistencia social) }\end{array}$ & $\begin{array}{l}\text { Porcentaje de la población del } \\
\text { quintil más pobre que está } \\
\text { cubierta por algún tipo de } \\
\text { programa de asistencia social }\end{array}$ & 100 & 5 & $\begin{array}{l}\text { Atlas de la Protección } \\
\text { Social del Banco } \\
\text { Mundial: Indicadores } \\
\text { de Resiliencia y } \\
\text { Equidad (ASPIRE) }\end{array}$ \\
\hline
\end{tabular}

\begin{tabular}{llccc}
\hline $\begin{array}{l}\text { Protección social } \\
\text { para los pobres }\end{array}$ & $\begin{array}{l}\text { Proporción de hogares pobres en } \\
\text { términos multidimensionales con } \\
\text { acceso a al menos uno de los } \\
\text { siguientes tipos de protección: i) } \\
\text { un miembro tiene alguna forma de } \\
\text { seguro de salud contributivo; ii) al } \\
\text { menos un miembro contribuye a } \\
\text { un sistema de seguridad social, y } \\
\text { iii) un miembro recibe una pensión } \\
\text { o un ingreso por jubilación }\end{array}$ & & Santos y otros (2015) \\
& $\begin{array}{l}\text { Gasto social en salud como } \\
\text { porcentaje del PIB }\end{array}$ & & \\
Gasto social \\
en salud
\end{tabular}

\begin{tabular}{lllll}
\hline $\begin{array}{l}\text { Gasto social en } \\
\text { protección social }\end{array}$ & $\begin{array}{l}\text { Gasto social en seguridad social y } \\
\text { asistencia como porcentaje del PIB }\end{array}$ & 13,50 & 0,30 & $\begin{array}{l}\text { Panorama social de } \\
\text { América Latina 2014 } \\
\text { (CEPAL, 2014b) }\end{array}$ \\
\hline
\end{tabular}

Fuente: Elaboración propia, sobre la base de Comisión Económica para América Latina y el Caribe (CEPAL), Panorama Social de América Latina 2013 (LC/G.2580), Santiago, 2013; Panorama Social de América Latina 2014 (LC/G.2635-P), Santiago, 2014; y M.E. Santos y otros, "A multidimensional poverty index for Latin America", OPHI Working Paper, $N^{\circ} 79$, Universidad de Oxford, 2015. 